\title{
The Making of the New European Wind Atlas - Part 2: Production and evaluation
}

\author{
Martin Dörenkämper ${ }^{1, \star}$, Bjarke T. Olsen ${ }^{2 \star}$, Björn Witha' ${ }^{3,4}$, Andrea N. Hahmann ${ }^{2}$, Neil N. Davis ${ }^{2}$ Jordi Barcons $^{5}$, \\ Yasemin Ezber $^{6}$, Elena García-Bustamante ${ }^{7}$, J. Fidel González-Rouco ${ }^{8}$, Jorge Navarro ${ }^{7}$, Mariano Sastre-Marugán ${ }^{8}$, \\ Tija Sïle $^{9}$, Wilke Trei ${ }^{3}$, Mark Žagar ${ }^{10}$, Jake Badger ${ }^{2}$, Julia Gottschall ${ }^{1}$, Javier Sanz Rodrigo ${ }^{11}$, and Jakob Mann ${ }^{2}$ \\ ${ }^{1}$ Fraunhofer Institute for Wind Energy Systems, Oldenburg, Germany \\ ${ }^{2}$ Wind Energy Department, Technical University of Denmark, Roskilde, Denmark \\ ${ }^{3}$ ForWind, Carl von Ossietzky University Oldenburg, Oldenburg, Germany \\ ${ }^{4}$ energy \& meteo systems GmbH, Oldenburg, Germany \\ ${ }^{5}$ Barcelona Supercomputer Center, Barcelona, Spain \\ ${ }^{6}$ Eurasia Institute of Earth Sciences, Istanbul Technical University, Istanbul, Turkey \\ ${ }^{7}$ Wind Energy Unit, CIEMAT, Madrid, Spain \\ ${ }^{8}$ Dept. of Earth Physics and Astrophysics, University Complutense of Madrid, Madrid, Spain \\ ${ }^{9}$ Institute of Numerical Modelling, Department of Physics, University of Latvia, Riga, Latvia \\ ${ }^{10}$ Vestas Wind Systems A/S, Aarhus, Denmark \\ ${ }^{11}$ Wind Energy Department, National Renewable Energy Centre (CENER), Sarriguren, Spain \\ ॠThese authors contributed equally to this work.
}

Correspondence: Martin Dörenkämper (martin.doerenkaemper@iwes.fraunhofer.de) and Bjarke T. Olsen (btol@dtu.dk)

Received: 24 January 2020 - Discussion started: 3 April 2020

Revised: 21 August 2020 - Accepted: 5 September 2020 - Published: 27 October 2020

\begin{abstract}
This is the second of two papers that document the creation of the New European Wind Atlas (NEWA). In Part 1, we described the sensitivity experiments and accompanying evaluation done to arrive at the final mesoscale model setup used to produce the mesoscale wind atlas. In this paper, Part 2, we document how we made the final wind atlas product, covering both the production of the mesoscale climatology generated with the Weather Research and Forecasting (WRF) model and the microscale climatology generated with the Wind Atlas Analysis and Applications Program (WAsP). The paper includes a detailed description of the technical and practical aspects that went into running the mesoscale simulations and the downscaling using WAsP. We show the main results from the final wind atlas and present a comprehensive evaluation of each component of the NEWA model chain using observations from a large set of tall masts located all over Europe. The added value of the WRF and WAsP downscaling of wind climatologies is evaluated relative to the performance of the driving ERA5 reanalysis and shows that the WRF downscaling reduces the mean wind speed
\end{abstract}

bias and spread relative to that of ERA5 from $-1.50 \pm 1.30$ to $0.02 \pm 0.78 \mathrm{~m} \mathrm{~s}^{-1}$. The WAsP downscaling has an added positive impact relative to that of the WRF model in simple terrain. In complex terrain, where the assumptions of the linearized flow model break down, both the mean bias and spread in wind speed are worse than those from the raw mesoscale results.

\section{Introduction}

Prior to every new wind turbine and wind farm installation, an energy yield assessment is carried out. This local energy yield assessment is typically based on a combination of wind speed measurements and model data (Rohrig et al., 2019). While the measurements are typically collected at a later stage of the planning phase, model data are used during many stages of the wind resource assessment. Thus, accurate modelling and evaluation of the modelling compared to observations is important. 
The initial evaluations of the wind conditions are typically based on numerical products, such as wind atlases, which generally provide convenient, fast, and easy access to estimations of the characteristic wind conditions at a site. Wind atlases have a long history in wind energy siting applications. In 1989, the European Wind Atlas (EWA, Troen and Petersen, 1989), one of the first comprehensive wind atlases, was published. It documents the meteorological basis for large parts of Europe and was the first wind atlas to be produced using the wind atlas method, a collection of statistical models that are the core of the Wind Atlas Analysis and Application Program (WAsP) software package (Mortensen et al., 2011). EWA was made based on a network of observational masts covering much of Europe, whose measured wind climate served as the input to the WAsP model.

Due to the ongoing advances of numerical weather prediction (NWP) models and the increase in available computational resources, modern wind atlases are typically based on numerical mesoscale model simulations. The wind climatologies (e.g. the long-term record of wind speed and direction at various levels in the boundary layer) from these simulations, can be downscaled using a microscale model, which can be of different levels of complexity and accuracy depending on the available computational resources and the complexity of the area of interest. However, in regions with homogeneous surface conditions, such as over the sea, over large lakes, grasslands, or deserts, it may be adequate to use the output directly from a mesoscale model to create wind atlases, as in, e.g.Peña Diaz et al. (2011) and Doubrawa et al. (2015). In regions with complex terrain, downscaling using a microscale model is typically applied. For smaller regions like counties or federal states, statistical-dynamical downscaling based on meso- $\gamma$-scale or microscale Computational Fluid Dynamics (CFD) Reynolds-Averaged NavierStokes (RANS) models can be applied (as in, e.g. MWKEL, 2013). For large regions, such as entire countries or continents, linearized flow models, such as WAsP, are most often used to reduce the computational demands (see e.g. GWA, 2019; Mortensen et al., 2014).

Since the start of the century, wind atlases have been produced for a large number of countries, including Egypt (Mortensen et al., 2006), South Africa (Mortensen et al., 2014; Hahmann et al., 2014, 2018), Finland (Tammelin et al., 2013), Germany (Weiter et al., 2019), Greece (Kotroni et al., 2014), Russia (Starkov and Landberg, 2000), and Iceland (Nawri et al., 2014), and for offshore regions, such as the Great Lakes in the USA (Doubrawa et al., 2015), the offshore Dutch Wind Atlas (Wijnant et al., 2019), the Southern Baltic Sea (Peña Diaz et al., 2011), and the Southern North Sea (Drüke et al., 2014). A comprehensive summary of national and regional wind atlases in Europe and can be found in Badger et al. (2018).

With the ongoing technical, computational, and scientific improvements since the release of EWA in 1989, a new updated wind atlas for Europe using current best practices and state-of-the-art models was needed (Petersen et al., 2013). To achieve this, the New European Wind Atlas (NEWA) project was created as a 4-year research project with the goals of creating such a wind atlas, collecting relevant field measurements for validation (Mann et al., 2017), and improving the model chain used for wind climate downscaling (Sanz Rodrigo et al., 2020). The NEWA wind atlas (Petersen, 2017) (https://map.neweuropeanwindatlas.eu, last access: 20 October 2020). consists of mesoscale and microscale datasets that cover all European Union member states, Norway, Switzerland, the Balkans, and Turkey. The mesoscale atlas was made using the Weather Research and Forecasting (WRF) model (Skamarock et al., 2008) and includes a number of both surface and boundary layer meteorological variables with a $3 \mathrm{~km} \times 3 \mathrm{~km}$ grid spacing. The resulting data are available at seven wind energy relevant heights for $30 \mathrm{~min}$ intervals over a 30-year period from 1989 to 2018. The WRF model output was downscaled using the WRF-WAsP methodology (Hahmann et al., 2020) to create the microscale atlas, which is a high-resolution atlas of the statistical wind climate covering the regions in a $50 \mathrm{~m} \times 50 \mathrm{~m}$ grid.

This paper is the second of two parts describing the modelling involved in the making of the NEWA Wind Atlas: the first paper (Hahmann et al., 2020b) deals with the sensitivity experiments that were carried out to guide the selection of the WRF model configuration used for the production of the mesoscale model simulations of the wind atlas. This paper, the second part, focuses on the production of the wind atlas, including a selection of the results and the evaluation of the wind atlas model chain using measurements from tall meteorological towers covering most of Europe.

Throughout this paper, we describe the configuration and model adaptations that were used to create the products of the NEWA wind atlas. In addition, issues such as the computational challenges and resources needed for producing a mesoscale wind atlas for the European continent and the parallelization of many millions of WAsP simulations are discussed. Finally, we present an evaluation of the ability of the final NEWA wind atlas to reproduce the spatial variability of the wind at a large number of tall masts in Europe. In Sect. 2 we introduce the models and the model setups and discuss the computational aspects of the wind atlas generation. Section 3 presents the main results and the evaluation of the atlas against mast data. In the last part of the paper, we discuss the results (Sect. 4), provide our conclusions (Sect. 5), and give a short outlook for potential future work that may build upon the results presented in this study.

\section{Wind atlas generation}

This section presents the mesoscale and microscale models used in the NEWA model chain to create the wind atlas products. In addition to introducing the models and their setup, 
the computational, technical, and logistical aspects of both modelling activities are presented.

\subsection{Mesoscale modelling: the WRF model}

\subsubsection{The WRF model}

The mesoscale wind atlas was created using the WRF model (Skamarock et al., 2008), which has a long record of use for wind energy applications, both onshore and offshore (e.g. Storm et al., 2009; Jimenez et al., 2010; Liu et al., 2011; Horvath et al., 2012; Karagali et al., 2013; Hahmann et al., 2015; Draxl et al., 2015; Dörenkämper et al., 2015; Lundquist et al., 2019). The setup of the WRF model used for the NEWA wind atlas is based on the evaluation of a large number of sensitivity experiments using mast data, which is documented in the first part of this study (Hahmann et al., 2020b).

The mesoscale model simulations of the NEWA production run use a modified version of the WRF model version 3.8.1, with changes in the Mellor-Yamada-Nakanishi-Niino (MYNN) planetary boundary layer (PBL) scheme (for details see Sect. 5.2 in Hahmann et al., 2020b). Furthermore, additional code that estimates ice accumulation was added to the WRF model code. This icing model is based on the ice growth model from Makkonen (2000) and adds additional output that can be used for estimating icing risk on wind turbines.

The 30-year mesoscale database is created by running a series of WRF model simulations: $7 \mathrm{~d}$ plus a $24 \mathrm{~h}$ spin-up period, which overlaps with the last day of the preceding weekly run. These relatively long simulations guarantee that the mesoscale flow is in full equilibrium with the mesoscale aerodynamic characteristics of the terrain, while nudging is used to keep the model solution from drifting away from the observed large-scale atmospheric patterns (Vincent and Hahmann, 2015). An advantage of the weekly runs is that the simulations are independent of each other and can be integrated in parallel. This reduces the total wall clock time needed to complete a multi-year climatology at a decent computational overhead. However, the state of the lower boundary, which is in equilibrium with the PBL conditions, is lost after each re-initialization, necessitating the $24 \mathrm{~h}$ of spin-up time.

All mesoscale simulations used three nested domains with a $3 \mathrm{~km}$ horizontal grid spacing for the innermost grid and a $1: 3$ ratio between the inner and outer domain resolution, leading to three different resolutions: $27 \mathrm{~km}$ for the outer domain (D1) and 9 and $3 \mathrm{~km}$ for the inner nested domains D2 and D3. The area to be covered by the NEWA wind atlas was divided into 10 independent high-resolution computational domains (named BA, CE, FR, GB, GR, IB, IT, SA, SB, and TR), as shown in Fig. 1. These are the innermost domains (D3), which all share the common outermost domain (D1). However, to further parallelize the simulations, each inner-

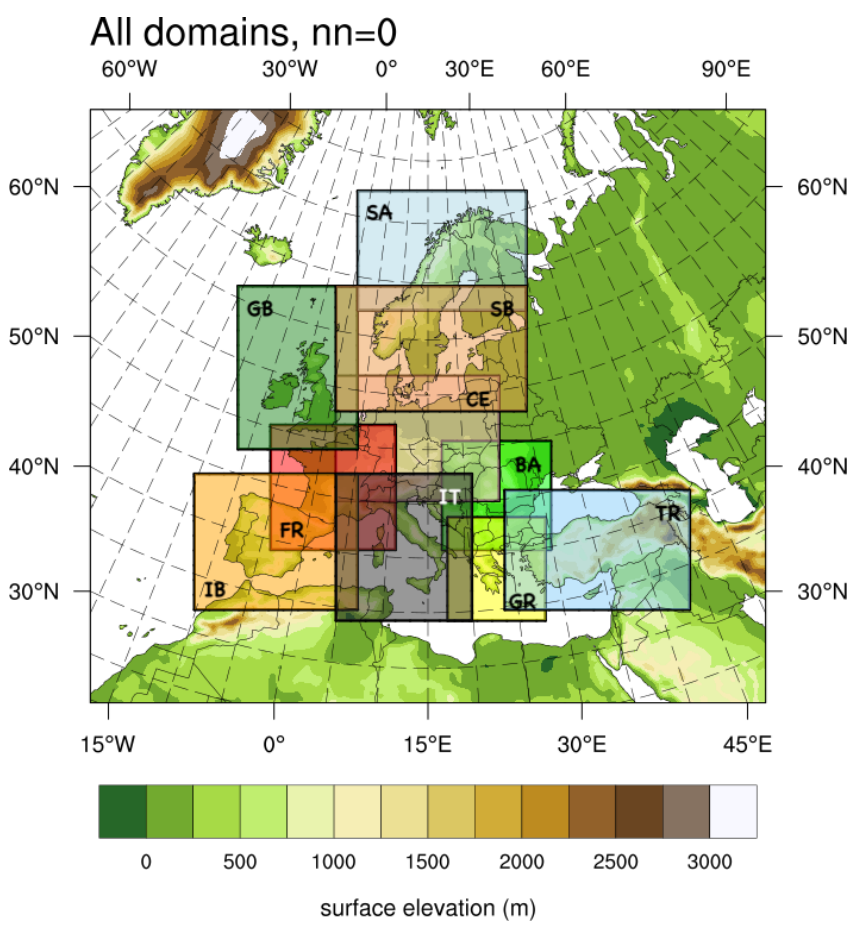

Figure 1. The location of $10 \mathrm{WRF}$ model domains (D3) used in the NEWA production run, excluding a 30 grid point buffer around each domain. The background map corresponds to D1, which is the same for all simulations. D2 domains are not shown Hasager et al. (reproduced from 2020).

most domain was run separately from the others. The 10 domains were created using the following rules:

1. Domains have to cover the NEWA area of interest: all European Union member states, Norway, Switzerland, the Balkans, and Turkey, as well as offshore areas $100 \mathrm{~km}$ off each coast and the complete North and Baltic seas.

2. Domains should not include large regions outside the NEWA area of interest.

3. Domains must be large enough so that each country is fully covered in one domain (exceptions: Norway, Sweden, and Finland).

4. Domains must have sufficient overlap: at least 30 grid points buffer at each domain boundary (following Wang et al., 2019).

The final domains vary in size from $325 \times 343$ grid points $(\mathrm{GR})$ to $631 \times 415$ grid points $(\mathrm{SB})$. All D2 domains have a blending zone of $350 \mathrm{~km}$ (or 39 grid squares) around the respective D3 domain. The common outer D1 domain is $250 \times 220$ grid points and corresponds to the background map shown in Fig. 1.

All other final WRF model setup parameters of the NEWA production runs are summarized in Table 1 . The above- 
Table 1. Setup configuration used in the NEWA production run.

\begin{tabular}{|c|c|}
\hline WRF version & 3.8.1 (modified PBL + icing code $)^{\mathrm{a}}$ \\
\hline Domains & 10 domains (see Fig. 1); Lambert conformal map projection \\
\hline Grid spacing $(\Delta x, \Delta y)$ & 3 nests: $27 \mathrm{~km}$ (D1), $9 \mathrm{~km}$ (D2), $3 \mathrm{~km}$ (D3); one-way nesting \\
\hline Vertical discretization & 61 vertical levels, model top at $50 \mathrm{hPa}$ \\
\hline \multirow[t]{2}{*}{ Model levels } & 20 model levels below $1 \mathrm{~km}$ \\
\hline & 10 lowest level heights: approx. $6,22,40,57,73,91,113,140,171,205$ m a.g.l. \\
\hline Simulation length & $8 \mathrm{~d}$ including $24 \mathrm{~h}$ spin-up \\
\hline Terrain data & Global Multi-resolution Terrain Elevation Data 2010 at $30 \operatorname{arcsec}$ (Danielson and Gesch, 2011) \\
\hline \multirow[t]{2}{*}{ Land use data } & CORINE 100 m (Copernicus Land Monitoring Service, 2019), \\
\hline & ESA CCI (Poulter et al., 2015) where CORINE not available \\
\hline Dynamical forcing & ERA5 (Hersbach and Dick, 2016) reanalysis $\left(0.3^{\circ} \times 0.3^{\circ}\right.$ resolution) on pressure levels \\
\hline Sea conditions & OSTIA (Donlon et al., 2012) SST and sea-ice $\left(0.05^{\circ}\right.$, approx. $\left.5 \mathrm{~km}\right)$ \\
\hline \multirow[t]{2}{*}{ Lake temperature } & Average ground temperature from ERA5, \\
\hline & Lakes are converted to ocean when temperature is present in OSTIA \\
\hline Nudging & Spectral nudging in D1 only, above PBL and level 20 \\
\hline Time step & Adaptive $(<5 \%$ failed $)$ \\
\hline PBL & MYNN (modified) (Mellor and Yamada, 1982) \\
\hline Surface layer & MO (Eta similarity) (Janjic and Zavisa, 1994) \\
\hline Land surface model & NOAH-LSM (Tewari et al., 2004) \\
\hline Cloud microphysics & WRF single-moment five-class scheme (Hong et al., 2004) \\
\hline Radiation & RRTMG scheme, 12 min calling frequency (Iacono et al., 2008) \\
\hline Cumulus parameterization & Kain-Fritsch scheme on D1 and D2 (Kain, 2004) \\
\hline Icing & WSM5 (Hong et al., 2004) + icing code + sum of qcloud and qice \\
\hline \multirow[t]{5}{*}{ Diffusion } & Simple diffusion \\
\hline & 2D deformation \\
\hline & 6th-order positive definite numerical diffusion \\
\hline & Rates of $0.06,0.08$, and 0.1 for D1, D2, and D3 \\
\hline & Vertical damping \\
\hline Advection & Positive definite advection of moisture and scalars \\
\hline Numerical options & 480 cores, IO quilting (one node used for output) \\
\hline
\end{tabular}

a The WRF code modifications are available from the NEWA GitHub repository: https://github.com/newa-wind/Mesoscale (last access: 20 October 2020).

mentioned WRF model code modifications, as well as the namelists and domain files for all 10 domains, are available from the NEWA GitHub repository (https://github.com/ newa-wind/Mesoscale, last access: 20 October 2020).

\subsubsection{Computational aspects}

The production run for the NEWA mesoscale was conducted between August 2018 and March 2019 on the MareNostrum 4 supercomputer that is operated by the Barcelona Supercomputing Center (BSC). For this purpose, computational resources to the amount of 57 million core hours were granted to the consortium via a PRACE (Partnership for Advanced Computing in Europe) proposal. The PRACE project was active, and the resources were available between April 2018 and March 2019. Besides the computational resources in terms of core hours, 100 terabytes (TB) of scratch space (for the temporary files of the runs) and an additional
$100 \mathrm{~TB}$ of project space (for storing, e.g. reanalysis input data and scripts) was available on the system.

As described in Sect. 2.1.1, the final setup for the production run was divided into 10 domains covering the EU, plus Norway, Switzerland, and Turkey. The estimated total mesoscale model output raw data (10 domains over 30 years) in $3 \mathrm{~km}$ spatial and $30 \mathrm{~min}$ temporal resolution would have resulted in a total of 6 petabytes. However, the final postprocessed wind atlas resulted in a much lower volume of around 0.2 petabytes (see below). Consequently, a partitioning of the full run into smaller runs that fit into the $100 \mathrm{~TB}$ of scratch space was essential, as was a high degree of automation of the runs, the post-processing, and the data transfer.

Figure 2 illustrates the split of the full wind atlas into separate computational tasks and the degree of automation of each part of the job chain. The full 30-year wind atlas for all 10 domains was first subdivided by the year and then by the domain. Each year-domain run (300 runs in total) then contained three array jobs of 52 or 53 elements each, one 


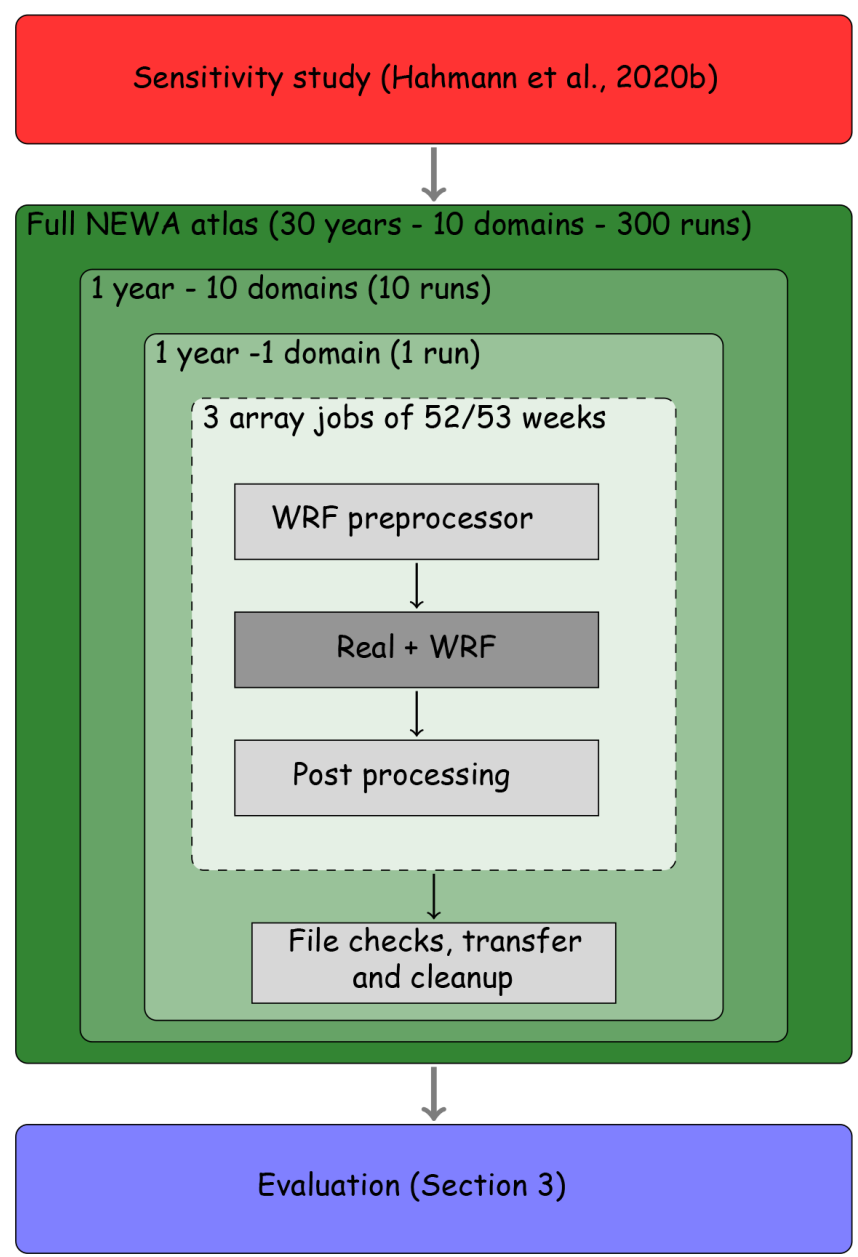

Figure 2. Illustration of how the production run was conducted. The dashed line encloses fully automatic processes, the dark grey box encloses the parallel process (here 480 cores), and light grey boxes enclose serial processes.

for each of the weekly runs. Out of these three array jobs, only the execution of the mesoscale run itself (real.exe and wrf.exe from WRFV3.8.1, indicated by the dark grey colour in Fig. 2) were run in parallel, using 480 cores each. All other tasks were run serially (light grey colour in Fig. 2).

The setup and submission of each year-domain set (three array jobs of 52 or 53 weeks each) was automated using a python3 script adapted to the properties of the computing cluster. It linked, copied, and adapted the necessary input files (e.g. namelists) and then submitted the job scripts to the queuing system. Dependencies were setup between each of the three stages of the job arrays to allow a full automation of the simulation process. This means that the array of jobs responsible for post-processing automatically started after the main runs were completed. In case of problems (e.g. hardware issues), a different script was used to manually resubmit single weeks of a year-domain run.
In total, each year-domain run occupied about $20 \mathrm{~TB}$ (from $13 \mathrm{~TB}$ for the GR domain to $23 \mathrm{~TB}$ for the SB domain) of scratch space, including all raw and post-processed data. Thus, it was possible to have up to five year-domain sets running at the same time within the space provided on MareNostrum 4. After a year-domain set completed successfully (i.e. the post-processing array run completed), a script for file checks, transfer, and cleanup was started. The filecheck portion of the script checked the post-processed output files for consistency and completeness. If the check proved successful, the post-processed files were moved to a special transfer directory and the raw data were deleted. On a dedicated server at the Technical University of Denmark (DTU), a cron job was constantly watching for post-processed files in the aforementioned transfer directory and initiated the transfer to the DTU server when new post-processed files were found.

During the production run, between August 2018 and March 2019, the mesoscale working group of the NEWA consortium (the authors of this study and further supporters) was constantly on standby. Each week a different person was on duty to launch, check, resubmit, and transfer runs $7 \mathrm{~d}$ a week to ensure fast progress and to avoid longer idle periods.

In terms of computational costs, each year-domain configuration spent $80000-140000$ core hours, leading to a total of about 35 million core hours for the full wind atlas. (The remaining PRACE grant was used for ensemble run calculations; see, e.g. González-Rouco et al., 2019). The resulting post-processed mesoscale time series (daily netCDF files following CF-1.6 conventions) contained the parameters given in Appendix A. The mesoscale wind atlas (30 years, 10 domains, 30 min resolution, 7 vertical levels) resulted in a total volume of around $160 \mathrm{~TB}$.

The final NEWA mesoscale wind atlas was created by combining the results from the individual mesoscale domains into a single merged mesoscale dataset for public use. Figure 3 shows how each domain contributed to the combined domain. Because all domains shared the same outer domain, reference location, and projection, the grid nodes of neighbouring domains overlap exactly, and therefore no interpolation was needed to combine them. Whenever possible, data for each country's exclusive economic zone come from the same mesoscale domain (cf. Fig. 1).

\subsection{Microscale modelling}

\subsubsection{The WRF-WAsP methodology}

The horizontal grid spacing of the mesoscale atlas is $3 \mathrm{~km}$ (in each direction) and cannot capture local flow features from sub-grid variations in orography and surface roughness. However, capturing these effects can be vital for accurately determining the local wind climate at a site (Sanz Rodrigo et al., 2017). 


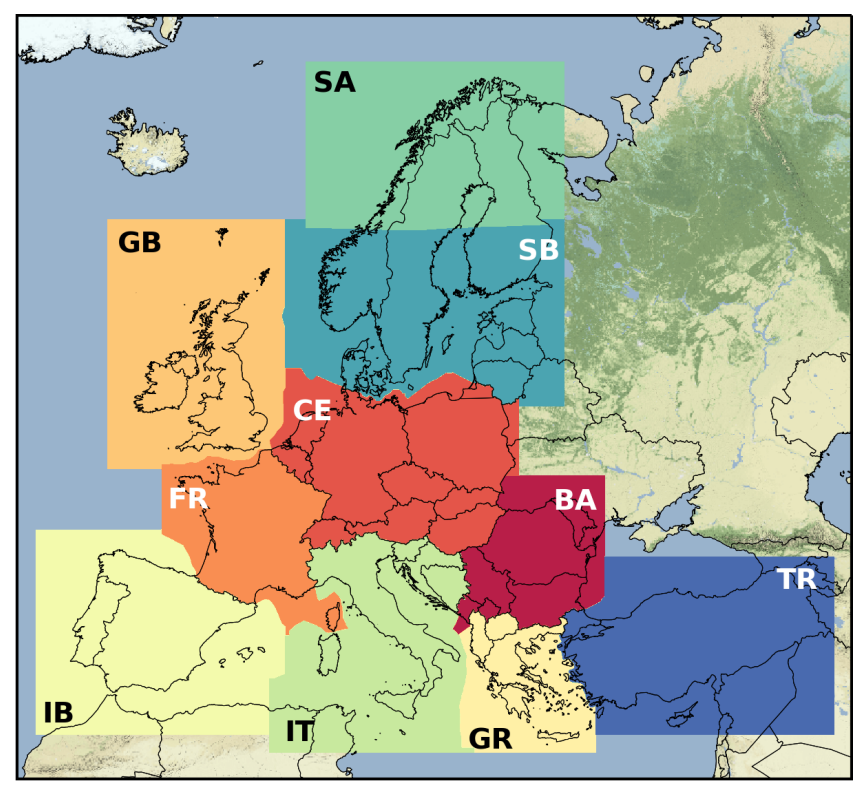

Figure 3. Map showing how the individual mesoscale domains are combined into a single merged dataset. Whenever possible the data for each country's exclusive economic zone come from the same domain. The background is the stamen terrain background from http://maps.stamen.com/terrain-background (last access: 30 October 2020) - (C) OpenStreetMap contributors 2020. Distributed under a Creative Commons BY-SA License.

Downscaling of the WRF-derived climatologies with a microscale model is needed for more accurate wind data, especially in non-homogeneous terrain. For this purpose, the WAsP microscale model was used (Troen and Petersen, 1989), following the WRF-WAsP downscaling methodology (Hahmann et al., 2014; Badger et al., 2014). Linearized flow models, such as the WAsP model, are well known and have been extensively used within the wind energy sector for site assessment in the past 30 years. Because the WAsP flow model is simple and computationally efficient, it can be applied to large areas.

The underlying principle of the WAsP methodology is to estimate the wind climate at a point by extrapolating horizontally and vertically from a measured wind climate at a nearby point. The extrapolation is done by first "removing" topographic effects (orographic, roughness, and obstacles) from the known wind climate estimated by the linearized flow model from the topographical maps of the area surrounding the known site. Then, vertical extrapolation is done using drag law relations. Finally, the topographic effects (estimated by the same model) at the target point are added to the wind climate. This method only works for short distances where it can be assumed that the geostrophic forcing remains constant.

The WRF-WAsP downscaling used here is analogous to the one used with a measured wind climate. However, instead of removing and adding topographical effects estimated from the same maps, the elevation and land use from the WRF model is used for "removing" topographical effects, and the best available maps are used for "adding" topographical effects. In WAsP, the wind climate at a given location is defined as the probability density of wind speed and wind directions. It can be represented as the probability density binned into a number of equal-width wind speed and wind direction bins or as a set of frequencies and best-fit Weibull distribution parameters for each sector.

As outlined above, the typical WRF-WAsP procedure involves two steps. First, the WRF model wind climate is "generalized", which removes the WRF local terrain effects from the WRF-simulated wind climate (i.e. the wind speed and sector statistics) to produce a new wind climate that is representative of a larger area surrounding the model grid cell. The generalized wind climate (in WAsP terminology) corresponds to the wind field distribution that would exist without orography and a homogeneous surface roughness, i.e. a flat surface of constant surface roughness. Therefore, the generalized wind climate varies only with height. In the WRFWAsP process, each generalized wind climate holds information, not just of the wind field distribution for a single surface roughness and height above ground level (a.g.l.) but instead for a number of preselected surface roughnesses and heights. In the second step, local terrain effects are "applied" to the generalized wind climate, resulting in a predicted wind climate. The local terrain effects vary based on the site location and height above the surface. The generalization procedure is carried out for all WRF model grid points, and the prediction procedure is carried out at each microscale model grid point and desired height. This results in a high-resolution map of the wind climate, i.e. the microscale wind atlas. The mean wind speed at $100 \mathrm{~m}$ for the microscale wind atlas is presented in Fig. 6c. The default procedure of WAsP is to represent the wind climate as binned wind speeds and directions during the generalization step until all corrections have been applied, then Weibull fits are made and used in subsequent steps.

In the WRF-WAsP methodology, the terrain effects for the generalization are derived from the gridded WRF model elevation and surface roughness, while the terrain effects used for prediction are estimated using the best available highresolution maps of elevation and surface roughness. The detailed technique for how these effects are calculated and used is described in Badger et al. (2014) for the mesoscale generalization and Troen and Petersen (1989) for the microscale prediction. All effects are taken into account using the default treatment of atmospheric stability in WAsP, which over land corresponds to an average heat flux of $-40 \mathrm{~W} \mathrm{~m}^{-2}$ and root mean square of $100 \mathrm{~W} \mathrm{~m}^{-2}$ and over sea corresponds to an average heat flux of $15 \mathrm{~W} \mathrm{~m}^{-2}$ and root mean square of $30 \mathrm{~W} \mathrm{~m}^{-2}$.

The NEWA long-term wind atlas, based on the 30 years of WRF model data, was made using the default WRF-WAsP downscaling method described above. The WRF model wind 
climates from these 30 years were generalized to heights of $50,75,100,150$, and $200 \mathrm{~m}$ a.g.l. and to surface roughnesses of $0.0002,0.03,0.1,0.4$, and $1.5 \mathrm{~m}$. Subsequently, predictions were made at heights of 50,100, and $200 \mathrm{~m}$ a.g.l. on a $50 \mathrm{~m} \times 50 \mathrm{~m}$ horizontal grid across Europe.

\subsubsection{High-resolution surface datasets}

The high-resolution terrain elevation was created by combining the Shuttle Radar Topography Coverage Version 3 (SRTM v3) dataset (Farr et al., 2007) south of $60^{\circ} \mathrm{N}$ and the ViewFinder DEM (de Ferranti, 2014) north of $60^{\circ} \mathrm{N}$. Both of these datasets have a $3 \operatorname{arcsec}(\approx 90 \mathrm{~m})$ resolution and are provided in the WGS84 map projection. The highresolution surface roughness length $\left(z_{0}\right)$ values were created based on the 2018 CORINE land cover dataset (Copernicus Land Monitoring Service, 2019), which has a horizontal resolution of $100 \mathrm{~m}$ and is in the ETRS89 Lambert Azimuthal Equal-Area map projection (EPSG 3035).

For downscaling with WAsP, the CORINE land cover classes were related to constant $z_{0}$ values through a lookup table (Table 2, "WAsP" column). Since no objective or thoroughly validated land use to surface roughness conversion exists for the CORINE land use classes, the accuracy of the table is highly uncertain. For WRF, the 44 CORINE land use classes were converted to the most similar 21 class USGS (Anderson et al., 1976) and converted to surface roughness length using constant values first suggested by Pineda et al. (2002) (see Table B1 in Appendix B for further details). Silva et al. (2007) proposed surface roughness values for the CORINE land use classes, but these were only validated for three sites in Portugal. A different conversion table, referred to as the DTU table, was proposed (Rogier R. Floors, Niels G. Mortensen, Andrea N. Hahmann, personal communication, DTU Wind Energy, March 2019) but has likewise not been comprehensively validated.

The $z_{0}$ values in the "WAsP" column in Table 2 were determined by using the DTU table as a starting point and then adjusting the values toward the corresponding $z_{0}$ in the WRF model table (Table 2, "WRF" column). Since the values in the DTU table are defined for the 44 CORINE classes, each class has a better characterization of a specific land use type. In contrast, each of the 21 USGS classes needs to represent a broader range of land use types. This means that the DTU table has more variation than the USGS table, and in most cases low roughness land use types have much lower $z_{0}$ values and high roughness land use types have much higher ones. The WAsP $z_{0}$ values were adjusted to be more like the WRF values to reduce the difference in the effective surface roughness between the two models and therefore reduce the risk of overcorrecting the wind climate when using the microscale model. For example, "non-irrigated arable land" and "pastures" are common land use classes in Europe (Table 2, "Proportion" column), and are respectively assigned roughnesses of 0.05 and $0.03 \mathrm{~m}$ in the DTU table (not shown).
However, in the WRF vegetation table, they are both assigned a value of $0.10 \mathrm{~m}$, which - everything else being equal - results in a large increase in the predicted wind speed when downscaling the WRF data for these classes. Similarly, locations with high $z_{0}$ values, such as forests and urban areas, experience the opposite effect. Therefore, the adjustment towards the WRF roughness values can be viewed as making the WAsP roughness corrections more conservative. For both the WRF simulations and the WAsP downscaling, the surface roughness values do not change with the seasons and are assumed to represent a seasonal geometric average.

\subsubsection{Computational aspects}

For easy interfacing with the WAsP model, the "PyWAsP" (PyWAsP, 2020) software package developed at DTU was used. PyWAsP is a python wrapper around the (mostly) Fortran-based WAsP core. The WAsP calculations are independent, making the downscaling procedure an "embarrassingly parallel" problem. However, to facilitate the 5.6 billion WAsP calculations that needed to be done, a two-tier parallelization process was employed, taking advantage of the cluster architecture used.

First, to split the work into manageable chunks, the wind atlas area was divided into 1402 tiles, each covering an area of $100 \mathrm{~km} \times 100 \mathrm{~km}$, and thereby consisting of $2000 \times$ 2000 calculation points (the target locations) spaced $50 \mathrm{~m}$ apart, adding up to the 5.6 billion calculations mentioned above. The tiles and all WAsP modelling was defined in the ETRS89 Lambert Azimuthal Equal-Area map projection (EPSG 3035) in metric units of metres. Each tile was submitted to a single computational node, with the load balancing of tile jobs managed by the HPC workload manager. To take advantage of the $32 \mathrm{CPU}$ cores on each compute node, each tile was divided into 2500 sub-tiles of $40 \times 40$ calculation points. The dask python package was used for scheduling and distribution of the computations needed for each of the sub-tiles across the different CPU cores.

To allow for each tile to operate as a stand-alone computational task, terrain and generalized wind climate data were created for each tile in advance. Natural neighbour interpolation (Sibson, 1981) was used to interpolate the generalized wind climates computed from the mesoscale model output to each target location. To ensure that a sufficient number of input wind climates were available around each target location for the interpolation, the wind climates included a $10 \mathrm{~km}$ buffer region around each tile.

Following WAsP best practices (Mortensen, 2018), a buffer area of $25 \mathrm{~km}$ around the tile should be enough to accurately model the influence of the orographic and surface roughness maps. However, this assumes some human judgement in the creation of the surface roughness map. WAsP uses the $z_{0}$ map in a couple of different ways. First a roughness rose is created. It contains information about upstream roughness changes in a number of radial sectors (typically 
Table 2. Surface roughness length [m] for each land use category in WAsP and WRF and the proportion it represents in the total dataset.

\begin{tabular}{|c|c|c|c|c|c|c|c|}
\hline Category & $\begin{array}{r}\text { Proportion } \\
(\%)\end{array}$ & $\begin{array}{l}\text { WAsP } \\
z_{0}(\mathrm{~m})\end{array}$ & $\begin{array}{r}\text { WRF } \\
z_{0}(\mathrm{~m})\end{array}$ & Category & $\begin{array}{r}\text { Proportion } \\
(\%)\end{array}$ & $\begin{array}{l}\text { WAsP } \\
z_{0}(\mathrm{~m})\end{array}$ & $\begin{array}{r}\text { WRF } \\
z_{0}(\mathrm{~m})\end{array}$ \\
\hline Continuous urban fabric & 0.1 & 1.0 & 1.0 & Broad-leaved forest & 8.0 & 1.0 & 0.9 \\
\hline Discontinuous urban fabric & 2.3 & 1.0 & 1.0 & Coniferous forest & 11.1 & 1.2 & 0.9 \\
\hline Industrial or commercial units & 0.4 & 0.7 & 0.5 & Mixed forest & 4.2 & 1.1 & 0.5 \\
\hline Road and rail networks and assoc. land & 0.1 & 0.2 & 0.5 & Natural grasslands & 2.9 & 0.1 & 0.1 \\
\hline Port areas & $<0.1$ & 0.5 & 0.5 & Moors and heathland & 2.4 & 0.12 & 0.12 \\
\hline Airports & $<0.1$ & 0.1 & 0.5 & Sclerophyllous vegetation & 1.5 & 0.12 & 0.12 \\
\hline Mineral extraction sites & 0.1 & 0.15 & 0.5 & Transitional woodland-shrub & 4.1 & 0.4 & 0.12 \\
\hline Dump sites & $<0.1$ & 0.15 & 0.5 & Beaches - dunes - sands & 0.1 & 0.01 & 0.01 \\
\hline Construction sites & $<0.1$ & 0.3 & 0.5 & Bare rocks & 1.3 & 0.05 & 0.01 \\
\hline Green urban areas & $<0.1$ & 0.8 & 0.5 & Sparsely vegetated areas & 3.2 & 0.03 & 0.01 \\
\hline Sport and leisure facilities & 0.2 & 0.3 & 0.5 & Burnt areas & $<0.1$ & 0.2 & 0.01 \\
\hline Non-irrigated arable land & 16.5 & 0.1 & 0.1 & Glaciers and perpetual snow & 0.2 & 0.005 & 0.001 \\
\hline Permanently irrigated land & 1.5 & 0.1 & 0.1 & Inland marshes & 0.2 & 0.05 & 0.001 \\
\hline Rice fields & 0.1 & 0.1 & 0.1 & Peat bogs & 1.6 & 0.03 & 0.001 \\
\hline Vineyards & 0.6 & 0.3 & 0.2 & Salt marshes & 0.1 & 0.02 & 0.001 \\
\hline Fruit trees and berry plantations & 0.6 & 0.4 & 0.2 & Salines & $<0.1$ & 0.005 & 0.001 \\
\hline Olive groves & 0.7 & 0.4 & 0.2 & Intertidal flats & 0.2 & 0.001 & 0.001 \\
\hline Pastures & 5.7 & 0.1 & 0.1 & Water courses & 0.2 & 0.0002 & 0.0001 \\
\hline Annual crops assoc. with perm. crops & 0.1 & 0.2 & 0.2 & Water bodies & 1.8 & 0.0002 & 0.0001 \\
\hline Complex cultivation patterns & 3.3 & 0.2 & 0.2 & Coastal lagoons & 0.1 & 0.0002 & 0.0001 \\
\hline Agriculture with sig. areas of nat. veg. & 3.7 & 0.2 & 0.2 & Estuaries & 0.1 & 0.0002 & 0.0001 \\
\hline Agro-forestry areas & 0.5 & 0.5 & 0.2 & Sea and ocean & 20.1 & 0.0002 & 0.0001 \\
\hline
\end{tabular}

12) and its distances to the point. For computational efficiency only the roughness changes that most impact the flow is kept (10 at most). These are identified based on the amount of total roughness variation they account for. The roughness rose is then used to calculate the upstream "background" roughness for the point and to model the internal boundary layers caused by the roughness changes. One of the key limitations of this approach is that the model assumes that the last roughness in the roughness rose continues to be the roughness indefinitely. Therefore, when creating a roughness map, it is important to look further upstream when making the map and to ensure that the outer roughness values match those found further upstream of the site. However, in our automated process this is not possible. This led to sensitivities in the sub-tile results, due to the inclusion of additional upstream roughness values when calculating the background roughness. To limit this impact, we included a preprocessing step that calculated the background roughness at a $1 \mathrm{~km}$ grid spacing using roughness maps that extended $100 \mathrm{~km}$ upstream from the grid point. When calculating the predicted wind climate, a $25 \mathrm{~km}$ map was used, but the preprocessed background roughness from a point approximately $30 \mathrm{~km}$ upstream was inserted into the roughness rose as the last roughness to reduce the sub-tile sensitivity.

In summary, to provide the correct background roughness to the WAsP model, the following steps were carried out for each sub-tile: (1) get coarse background roughness from a pre-processed map, (2) create the roughness rose, (3) add coarse background roughness as the last bin of the roughness rose, and (4) calculate the roughness site effects using the updated roughness rose. The computational time for the simulation of the tiles varied considerably, between 1 and $14 \mathrm{~h}$ for each tile, depending on the complexity of the terrain.

\subsection{Evaluation methodology}

It is not possible or appropriate to evaluate the wind climatology of the wind atlas itself (e.g. what is available for download from the NEWA site) because it represents a long climatological period (1989-2018) and no wind speed measurements span that entire period at wind energy relevant heights. Instead, the NEWA model chain is validated by using it to create individual wind climates for 291 tall masts covering Europe, such that the wind climates represent the exact measurement periods covered by each mast. This section covers the metrics used to describe the terrain complexity at each site, followed by a description of the masts' measurement data. Finally, we describe a number of modifications to the WRF-WAsP methodology made specifically for the evaluation against mast data.

\subsubsection{Terrain complexity}

To quantify the relationship between model biases and the complexity of the terrain at the sites, several metrics related to the orographic and surface roughness complexity were calculated for each site. In this paper we focus on the ruggedness index (RIX) (Mortensen et al., 2008), which was used to 
quantify the orographic complexity. The RIX number is defined as the fractional extent of the terrain that exceeds a critical slope, in this case $16.7^{\circ}$, within $3500 \mathrm{~m}$ of the point of interest. The RIX number is used in WAsP to indicate terrain where the surrounding orographic slopes are steeper than the valid limits of the flow model (IBZ Jackson and Hunt, 1975) and thus where the orographic speed-ups are expected to be overestimated.

Additionally, three metrics to quantify the surface roughness heterogeneity were investigated for each site. First, the degree of variation of the surface roughness around the sites was used to identify sites that would likely have complex structures in the flow due to rapid changes in the surrounding surface roughness. Second, the distance from the mast location to the nearest coastline was used to detect coastal influences on the model biases. Third, the average aggregate upstream surface roughness at the site was used to detect biases associated with high or low roughness sites.

Initial analysis showed that each of the surface roughness metrics explained some of the variance of the model biases. However, it was clear that the RIX number explained most of the variance for both the ERA5 and WAsP results and a large amount of the variance in the WRF model results. Therefore, only the RIX number is included in the remaining analysis.

\subsubsection{Observed data}

The results of the NEWA model chain were validated against measurements from 291 tall masts made available for the study. Because the data are proprietary, only aggregated results are presented. Figure 4 shows the number of masts located in each country. Large variations in the number of masts present in each country and across regions exist, e.g. just 4 masts in Germany and Spain, while 38, 42, and 44 masts are located in Poland, Italy, and Turkey, respectively. However, most parts of Europe and Turkey are well represented.

Figure 5 shows the distribution of several descriptive variables for the 291 masts. All measurements used in the evaluation were taken on tall meteorological masts. Cup or sonic anemometers were used for the wind speed measurements, either from a single instrument or via an optimal sampling of measurements from two instruments mounted on opposing booms to reduce flow distortion effects. Only measurements $40-150 \mathrm{~m}$ a.g.1. were used for the evaluation (Fig. 5b) in order to avoid the large uncertainties associated with wind speed measurements near the surface and to ensure that the measurements are representative of modern and future turbine hub heights. Wind direction measurements were taken either from the sonic anemometers or from wind vanes as close to the wind speed measurements as possible (typically $0-40 \mathrm{~m}$ below the wind speed instrument). The measurements were previously quality controlled by applying an inhouse method of the data provider and were further checked for obvious measurement errors like icing and non-physical

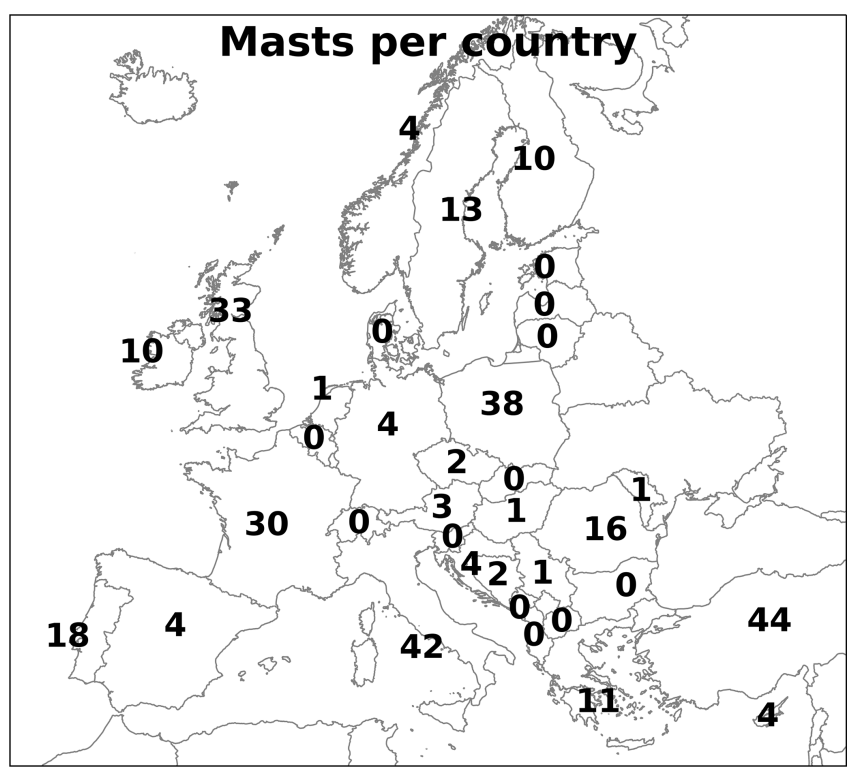

Figure 4. The number of masts located in each country in Europe. For several smaller countries the number has been omitted for readability (all of them have zero masts).

(e.g. repeated) signals for this study based on $10 \mathrm{~min}$ averages; fortunately no problems were detected. Because no flow distortion correction was made to measurements from masts with a single instrument at the measurement height, we expect flow distortion to have some influence on the results. We estimate the effect to be up to a few percent difference in annual mean wind speed for those masts, based on the impact of including such correction in Hahmann et al. (2020b) and indications by, for example, Westerhellweg et al. (2012).

A total of 12 months of measurements were used from each mast to ensure that the results were not biased due to differences in sample sizes. The period with the highest availability of measurements (between 2007 and 2015) was chosen. For most masts, the best period occurred after 2009 (Fig. 5a). To avoid biases due to seasonal variations in data availability, an additional requirement that at least $80 \%$ of the possible data were available for each month was stipulated. For most masts, more than $90 \%$ of the possible data were recovered every month.

The RIX values for the masts (Fig. 5c) shows a skewed distribution, with most values found below $2 \%$, and only a few masts with very large values. For further analysis, the masts were grouped into three RIX groups: low: $0 \%(n=$ 110); medium: 0\%-2\% $(n=96)$; and high: $2 \%(n=85)$ or greater (dashed lines in the figure). These thresholds were chosen to ensure a similar number of masts in each group. 

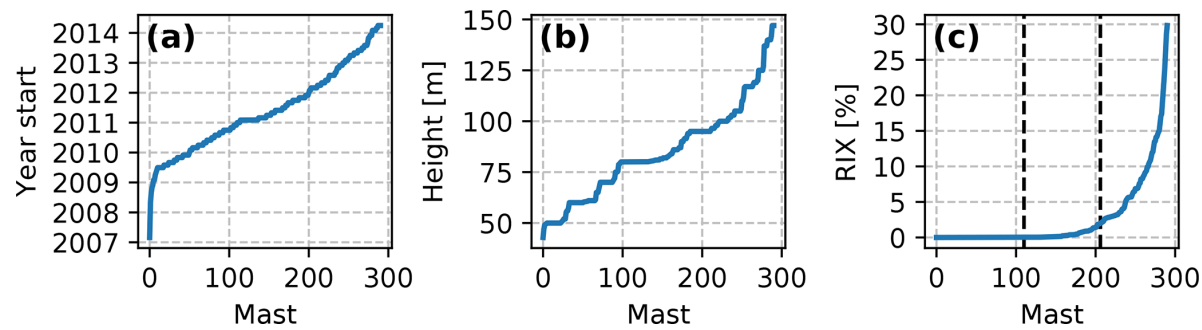

Figure 5. Ranked values of metadata variables for the 291 masts: (a) the start year of the 1-year period, (b) the height a.g.1. of the wind speed measurements, and (c) the ruggedness index (RIX). The dashed vertical lines in (c) shows the separation (greater than $0 \%$ and greater than $2 \%$ ) of the masts into groups by RIX.
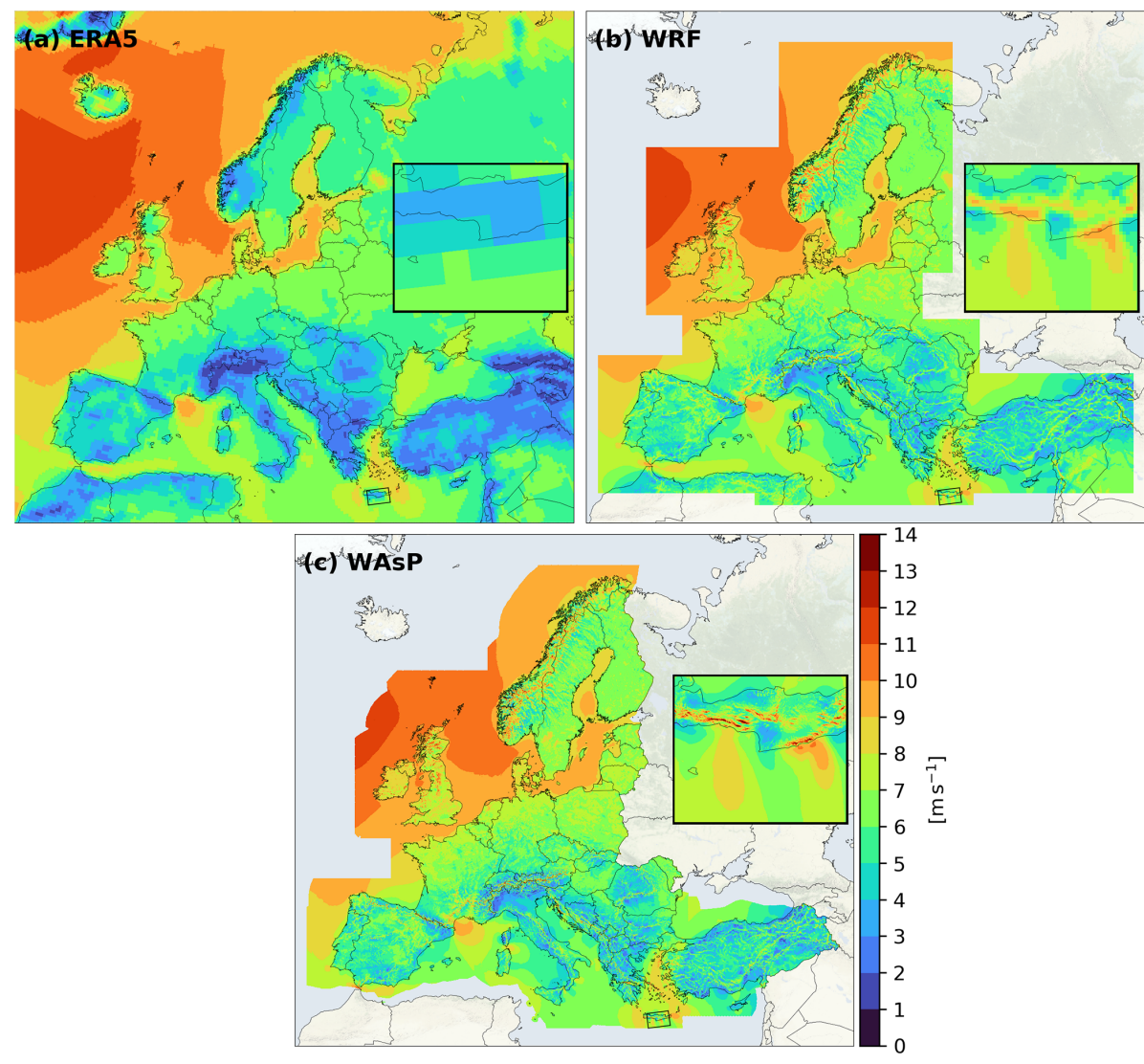

Figure 6. (a) ERA5, (b) WRF, and (c) WAsP mean wind speed at $100 \mathrm{~m}$ a.g.l. averaged over the full 30-year period (1989-2018). The zoom-in shows the results for the island of Crete. Additional details can be seen on the NEWA wind atlas website https://map.neweuropeanwindatlas. eu/ (last access: 20 October 2020). The map background is the stamen terrain-background from http://maps.stamen.com/terrain-background (last access: 20 October 2020) - (C) OpenStreetMap contributors 2020. Distributed under a Creative Commons BY-SA License.

\subsubsection{Adjustments to WRF-WAsP downscaling used for evaluation against mast data}

For evaluation of the downscaled wind climate at each mast site, some modifications to the WRF-WAsP methodology were made. First, the measurements and the WRF model data for the mast location (nearest grid cell) were obtained, ensuring that the WRF data were concurrent to the measurements. Second, instead of a two-step process (generalization and prediction) with Weibull-fitting used after the generalization step, the corrections due to terrain effects from both steps were applied to the binned wind climate during the same (single) step. Third, since the WRF output was interpolated to $50,75,100,150$, and $200 \mathrm{~m}$, we used the height closest to the height of the measurements, thus the largest vertical extrapolation required was less than $25 \mathrm{~m}$ and on average it was just $6.8 \mathrm{~m}$. The probability density of the original bin is distributed to the nearest bins in the new binned 
wind climate. After repeating this for every bin of the original wind climate, the new predicted binned wind climate is complete. Neutral atmospheric stability was assumed for the vertical extrapolation from WRF output height to the height of the measurements, and the stability correction of Weibull parameters (Troen and Petersen, 1989), which is normally made to the generalized wind climate, was omitted.

This alternative approach has some advantages over the default approach: a Weibull distributed wind is not assumed, so no parameterization biases occur. This is a particular advantage for shorter periods, i.e. months, but may also be advantageous for 1-year periods, such as those used here. Also, when the generalization and prediction is done in one single step, one avoids the truncation errors that occur when the wind climate is generalized to fixed generalization heights and surface roughness and then subsequently interpolated to a new height and surface roughness for the predicted wind climate at the site. The impact of these differences between the default WRF-WAsP approach and the alternative approach was estimated for the 1-year wind climates at the validation sites. For the mean wind speed, the differences are of the order of one percent due to Weibull-fitting and similarly for the stability correction. A direct comparison between the WRF-WAsP downscaling over the entire map and that at the sites is not possible, but the differences should similarly be on the order of a few percent. This issue is discussed further in Sect. 4.

\section{Results}

\subsection{The wind atlas}

Figure 6 shows one of the main results of the NEWA wind atlas, the map of the wind speed at $100 \mathrm{~m}$ averaged over the full 30-year period (1989-2018) derived from the mesoscale simulations and downscaling with WAsP. The difference in the wind speed between onshore and offshore sites is evident in many areas. Local wind systems like the Mistral, the Bora, and the flow through the Strait of Gibraltar (Levante and Poniente) are clearly visible. Due to the limited resolution, some of these flows are not fully resolved in commonly used reanalysis datasets like ERA5 (Hersbach and Dick, 2016) and CFSRv2 (Saha et al., 2014) or MERRA2 (Gelaro et al., 2017) (not shown here). The inset figures in Fig. 6 show the flow around the Greek island Crete, which is heavily influenced by the Etesian winds. ERA5 and WRF both capture these winds, but differ significantly in magnitude over and in the lee of Crete. It is also clear that additional flow features have been resolved by WRF, e.g. gap flows in the mountains of Crete. The microscale downscaling with WAsP adds additional details especially over the complex coastal mountain ridges. Additional details and a comparison with satellite data for this local wind system are provided in Hasager et al. (2020).
Additional terrain effects along large mountain ridges can be seen, including the highest wind speeds in Europe, occurring in Central Norway, and areas in the Alps that have wind speeds above $10 \mathrm{~m} \mathrm{~s}^{-1}$. As expected, the microscale downscaling results in larger flow variations in mountainous areas, as exemplified in the inset figure. Thus, the wind speeds on the mountain tops are slightly higher.

Figure 7 shows the differences in the $100 \mathrm{~m}$ mean wind speed between WRF and ERA5 (a) and WAsP and WRF (b) for the full 30-year period. To calculate the differences the lower-resolution data were interpolated bi-linearly to the grid of the higher-resolution dataset, which is not typically recommended, but is done here for illustration purposes. For convenience, the difference between WAsP and WRF was not calculated on the native $50 \mathrm{~m}$ WAsP grid but on a downsampled grid corresponding to every 10th point in north and east directions, i.e. with a $500 \mathrm{~m} \times 500 \mathrm{~m}$ spacing. In general, it is clearly visible that the mesoscale model resolves the terrain better than the reanalysis and thus captures more of the variation due to orography, e.g. the larger wind speed on top of mountain ridges. On the large European scale, however, the differences between mesoscale and microscale are small, especially in areas of low terrain complexity. However, over very complex topography (e.g. in the Alps and Pyrenees) the WAsP downscaling greatly increases the wind speed. This is studied in more detail in Sect. 3.2.

The post-processed mesoscale and microscale fields can be accessed interactively on the NEWA website: https://map. neweuropeanwindatlas.eu/ (last access: 20 October 2020).

\subsection{NEWA model chain evaluation}

The evaluation of the NEWA model chain performed by comparing the wind climates estimated at each stage of the model chain: ERA5 (forcing reanalysis), ERA5+WRF (mesoscale, simply labelled "WRF"), and ERA5+WRF+WAsP (microscale, simply labelled "WAsP") to the observed wind climates. By comparing the wind climates, it is not possible to evaluate the time-dependent aspects of the NEWA model results, which, additionally, are not available from the WAsP model. Further analysis of timedependent aspects are included in the NEWA uncertainty report (González-Rouco et al., 2019).

The WRF- and ERA5-derived wind climates are calculated from the time series of wind speed and direction, and interpolated linearly in time and space to the mast location and height for times concurrent with the measurements. The WAsP wind climates were estimated using the method outlined in Sect. 2.2.

\subsubsection{Mean wind speed biases}

The relationship between the observed and modelled mean wind speeds for the validation periods for the 291 masts are presented in Fig. 8. The same point scatter is repeated in 


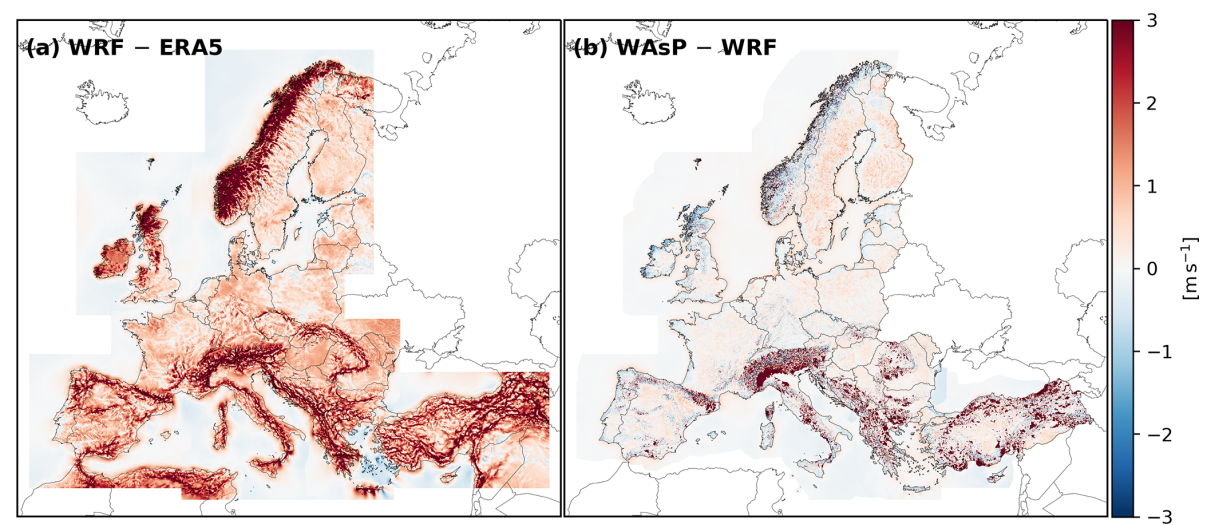

Figure 7. Mean wind speed differences for WRF minus ERA5 (a) and WAsP minus WRF (b) at $100 \mathrm{~m}$ a.g.l. averaged over the full 30-year period (1989-2018). Note that the lower resolution data were interpolated bi-linearly to the grid of the dataset with higher resolution. The difference between WAsP- and WRF-derived winds was calculated on a down-sampled version of the WAsP grid with a grid spacing of $500 \mathrm{~m} \times 500 \mathrm{~m}$.

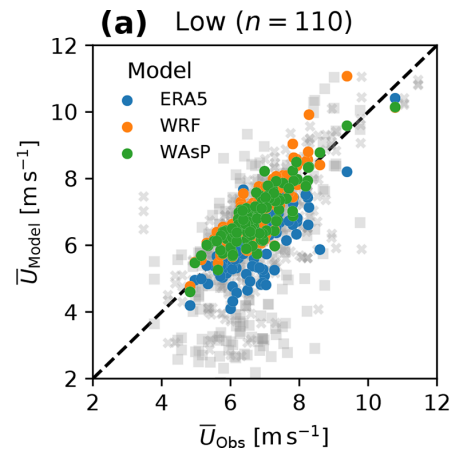

(b) Medium $(n=96)$

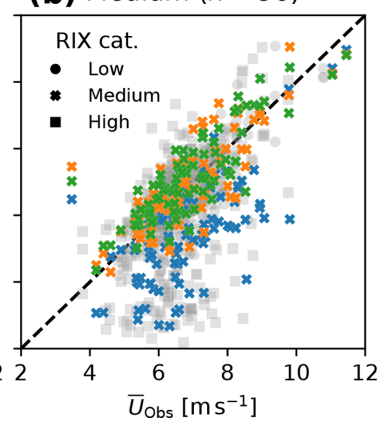

(c) High $(n=85)$

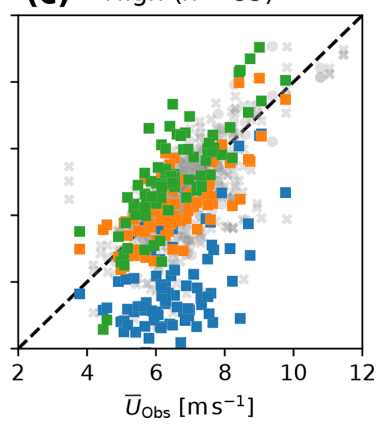

Figure 8. Observed versus modelled mean wind speed for ERA5, WRF, and WAsP. The three subplots include the same scatter points, but each of them highlight a different ruggedness index (RIX) category: low (a), medium (b), and high (c). The number of masts $(n)$ in each category is indicated above the subplots.

three subplots, each with samples from one of the three RIX groups highlighted with colours and the remaining samples greyed out (Fig. 8). The corresponding distributions of mean wind speed biases, computed as the model minus the observation values, are shown in Fig. 9. The smallest spread and least scatter in mean wind speed from all three downscaling stages (ERA5, WRF and WAsP) is at low RIX sites and is considerably larger at medium and high RIX sites. This result is not unexpected and shows that the uncertainty in all three models increases as the orographic complexity of the site increases.

The overall mean wind speed bias for all the masts is $-1.5 \mathrm{~m} \mathrm{~s}^{-1}$ for ERA5, while it is $0.28 \mathrm{~m} \mathrm{~s}^{-1}$ and virtually zero for the WAsP and WRF wind speeds, respectively (Fig. 9). The sample means of the RIX groups show that the biases of the ERA5 and the WRF wind speeds become more negative with increased complexity. This is possibly due to under-resolved orographic speed-up effects occurring at the more complex sites, since these masts tend to be placed on top of hills and ridges, where stronger wind is expected. For both ERA5 and WRF, the spread for biases in the mean wind speed are comparable between the samples in medium and high RIX classes, but slightly smaller for high RIX.

The mean biases in wind speed from WAsP and WRF are most similar in simple terrain, where the WAsP model makes the smallest adjustments to the WRF model wind climates (Fig. 9). The adjustments that are made by WAsP cause a reduction in the bias relative to the ones from WRF (from 0.21 to $0.06 \mathrm{~m} \mathrm{~s}^{-1}$ ) and spread (from 0.54 to $0.49 \mathrm{~m} \mathrm{~s}^{-1}$ ). The bias of the WAsP wind speeds (overestimation) and spread increase with increasing complexity, indicating that the linearized flow model in WAsP has too large of an orographic wind speed speed-up for many of the sites in medium and high RIX especially, as is expected.

The aggregate statistics of the mean wind speed biases presented in Fig. 9 do not show the spatial dependencies of the biases. However, some of these patterns are revealed in Fig. 10, which shows boxplots of the mean wind speed biases for the three stages of the model chain in the 11 countries with the most masts. The countries generally have low 

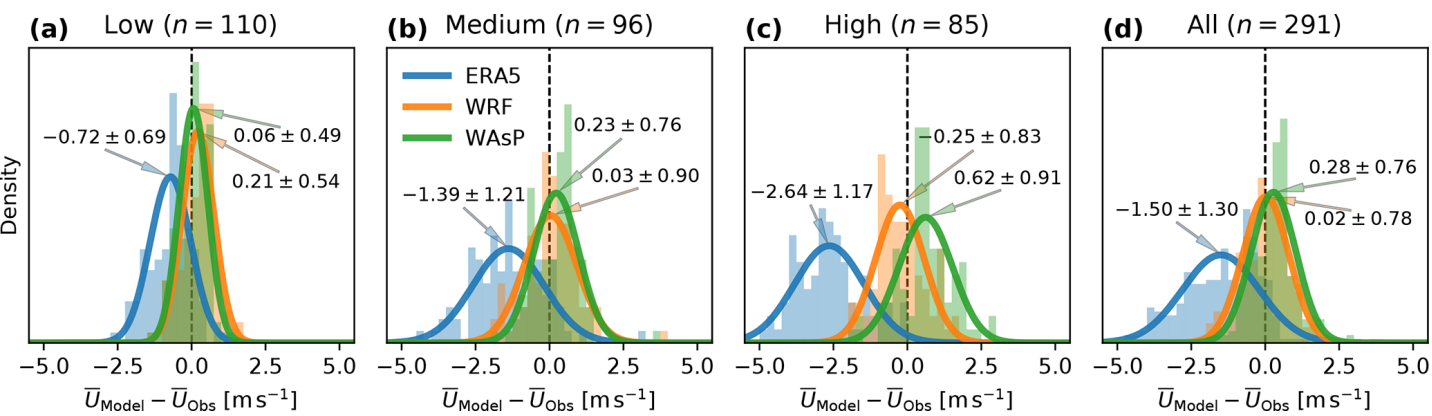

Figure 9. Distributions of wind speed biases $\left(\bar{U}_{\text {Model }}-\bar{U}_{\text {Obs }}\right)$ for ERA5, WRF, and WAsP split by ruggedness index (RIX) category: low (a), medium (b), high (c), and all of the samples combined (d). Fitted normal distributions (lines) are annotated by the mean and standard deviation of the samples $(\mu \pm \sigma)$. The number of masts $(n)$ in each category is indicated above the subplots.

Country ( $n$ in low-medium-high RIX)

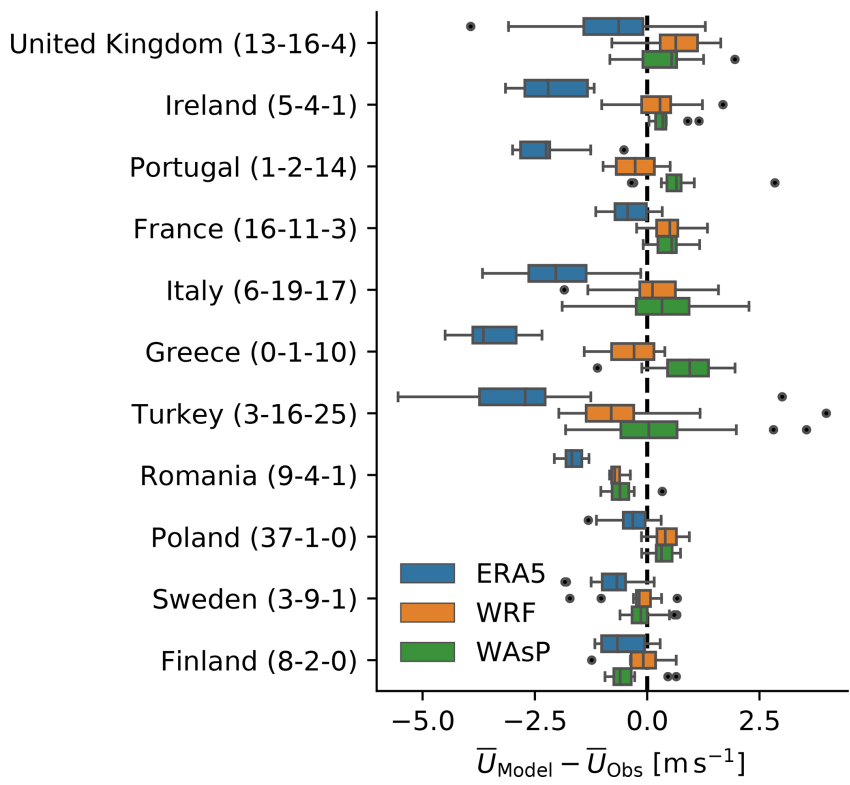

Figure 10. Boxplots of the distribution of mean wind speed biases $\left(\bar{U}_{\text {Model }}-\bar{U}_{\text {Obs }}\right)$ by ERA5, WRF, and WAsP for the 11 countries containing most masts. The number of masts in each ruggedness index (RIX) category is shown in the parenthesis. The boxes indicate the 2 nd and 3 rd quartiles. Whiskers extend to $1.5 \times$ the interquartile range (extent of 2 nd and 3 rd quartile) or to the outermost data point. Points indicate outliers outside the $1.5 \times$ interquartile range.

or high complexity, with a few having an even mix. As expected, Fig. 10 shows that both the bias and the spread of the biases are larger in countries with many sites in highly complex terrain, e.g. Turkey and Italy. However, significant differences in biases exist in some countries with mostly simple sites, e.g. the underestimation in Romania and overestimation in Poland by WRF and WAsP. These differences may be caused by biases associated with the large-scale flow included in the ERA5 reanalysis data that WRF cannot correct, which influences the bias on a region scale as opposed to, for example, local influences from the terrain. Systematic biases in the measurements, e.g. from the same technical personnel and instrumentation at nearby clusters of masts, can not be ruled out either. The WAsP results generally follow the WRF results in simple terrain and deviate more in complex terrain, where the WAsP results tend to have larger wind speeds than those from WRF. Finland is a curious exception where the WAsP results have decreased the mean wind speed compared to those from WRF. The land use near the Finnish sites is mostly dominated by water bodies, coniferous and mixed forests, and grasslands and pastures. Thus, the decrease may be related to an increase in effective surface roughnesses in WAsP associated with a larger influence of forests or an overestimation of the surface roughness assigned to the forest classes.

Additional analysis (not shown) revealed that the mean wind speed biases of all three models are highly linked to spatial patterns. For ERA5 there is a tendency of reduced underestimation of the mean wind speed with latitude, with the largest underestimations found in the south (Italy, Greece, and Turkey in particular) and smaller, but still generally negative, biases found further to the north (Poland, France, and Scandinavia in particular). In contrast, WRF shows that a negative trend in mean wind speed error exists with longitude, with slightly larger negative biases found further to the east (Romania, Turkey, and Greece in particular) than to the west (UK, Ireland, and France in particular). The orographic complexity obviously has a strong spatial dependency as well, and thus latitude and longitude are not independent of RIX, which can explain some of this spatial dependency. But other contributing factors also play a role, this could be, for example, spatially correlated biases related to large-scale patterns in the flow. For WAsP, RIX explains most of the variance of mean wind speed biases. This makes sense, bearing in mind the previous results, which show how the wind speed speed-ups in orographically complex terrain cause large overestimations.

WAsP mean wind speed biases tend to be larger for lower heights above the surface. Since this is not seen for WRF, it suggests that the WAsP terrain or vertical extrapolation ef- 
fects are overestimated closer to the surface. However, the tallest measurements are more frequent in low-RIX terrain, and smaller masts are more frequent in the high-RIX terrain, and so some degree of collinearity exists between RIX and mast height, which could explain some of these differences.

Further analysis (not shown) also suggested that the variation of the surface roughness magnitude and complexity are not primary factors explaining the variation in mean wind speed bias for the three stages of the NEWA model chain. Surface roughness effects are, by definition, important for the magnitude of the wind speed at each site because of the momentum drain it exerts on the flow. Thus, the fact that it does not show any strong relation to the wind speed biases suggests that mean wind speed biases are not systematically associated with mischaracterization of the effective surface roughness or of internal boundary layer effects.

\subsubsection{Mean power generation biases}

Ultimately, for the application of the NEWA wind climate estimates, the accuracy of the estimated power production is more important than capturing the mean wind speed. This requires the accurate simulation of the entire wind speed probability density function, and particularly the most critical wind speeds of the turbine-specific power curve, on the steepest part of the power curve.

To illustrate the accuracy of the NEWA wind climates for simulating the mean power generation of one specific turbine, the NREL $5 \mathrm{MW}$ power curve was used as an example (Fig. 11). The non-linearity of the power curve enhances the relative importance of a limited range of wind speeds of the wind speed PDF where the power curve is steepest (in this case $8-12 \mathrm{~m} \mathrm{~s}^{-1}$ ). Since power curves can be quite different from turbine to turbine, the results for the NREL $5 \mathrm{MW}$ turbine are not general, and could vary substantially depending on what turbine is used.

The mean power generation biases, in percentage, are defined as

$\bar{P}_{\text {Bias }}=100 \times \frac{\bar{P}_{\text {Model }}-\bar{P}_{\text {Obs }}}{\bar{P}_{\text {Obs }}}$,

where $\bar{P}_{\text {Model }}$ and $\bar{P}_{\text {Obs }}$ in $\mathrm{W}$ are the estimated mean power generation from the model and the measurements, respectively, calculated using the full simulated wind speed distribution.

The distributions of the biases in the mean wind power generation $\left(\bar{P}_{\text {BIAS }}\right)$ for the three stages of the model chain is shown in Fig. 12. The mean wind power generation is calculated as the sector-weighted mean from the binned wind distribution convolved with the power curve. For the 291 masts, the underestimation of the wind speed in the ERA5 results in a large underestimation of the mean generated power, $-40.2 \% \pm 32.7 \%$. This underestimation is especially large in high RIX terrain $(-69.4 \% \pm 24.9 \%)$. In low RIX terrain, the underestimation is also fairly large $(-20.5 \% \pm 20.5 \%)$.

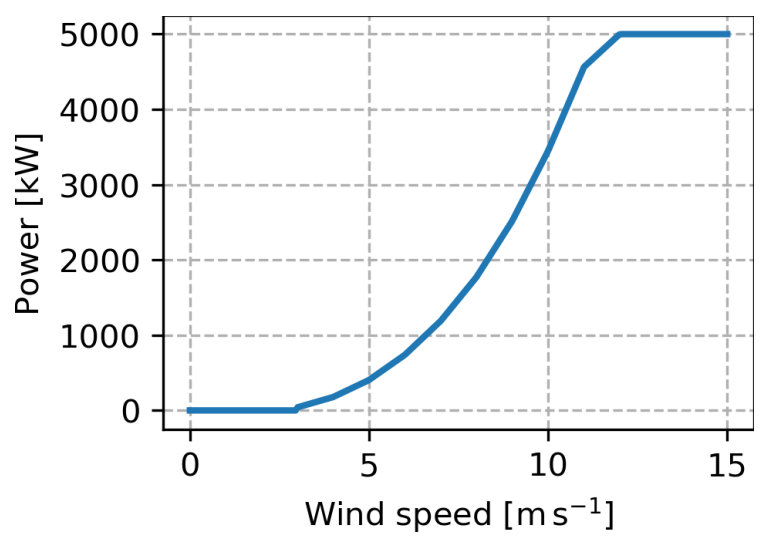

Figure 11. Power curve for the NREL $5 \mathrm{MW}$ reference wind turbine (Jonkman et al., 2009).

Since the percent biases are lower-bounded at $-100 \%$, the ERA5 biases in the high RIX group do not follow the fitted Gaussian distribution well (the median value is $-78.14 \%$ ). A Poisson distribution may describe the distribution better, but for simplicity the normal distribution is used regardless.

The power estimated using the WRF model winds has the lowest average error $(6.2 \% \pm 25.2 \%)$ across all masts. The distributions of power biases separated into groups by RIX class follow a similar pattern to the one seen for wind speed biases: the spread is smallest in simple (low RIX) orography $(11.3 \% \pm 18.3 \%)$, but the overall bias is larger than in medium $(7.4 \% \pm 29.1 \%)$ and high $(-1.8 \% \pm 26.2 \%)$ complexity sites.

For all the masts, the average mean power generation estimated from WAsP winds is overestimated by $13.3 \% \pm$ $27.4 \%$. In low RIX terrain, a reduction of mean power bias and spread is seen compared to the WRF results, however the power is still overestimated $(7.3 \% \pm 17.6 \%$ on average). In medium RIX terrain, just like for mean wind speed, the spread of mean power is reduced relative to WRF, but the average overestimation is enhanced by WAsP. In the most complex orography (high RIX), WAsP significantly overestimates the power and increases the spread of $\bar{P}_{\text {Error }}$ $(21.2 \% \pm 36.7 \%)$ relative to the estimates made with WRF simulated winds.

\subsubsection{Wind direction biases}

The Earth Mover's Distance (EMD) score based on a circular distance matrix between modelled and observed wind direction CDFs (CEMD $\left.{ }_{W D}\right)$ is used to evaluate the modelling biases in the wind direction distributions of the wind climates. The EMD can generally be understood as the amount of physical work needed to move a pile of soil in the shape of one distribution to that of another distribution and is introduced in more detail in Part 1 of this study (see Sect. 4 in Hahmann et al., 2020b). 

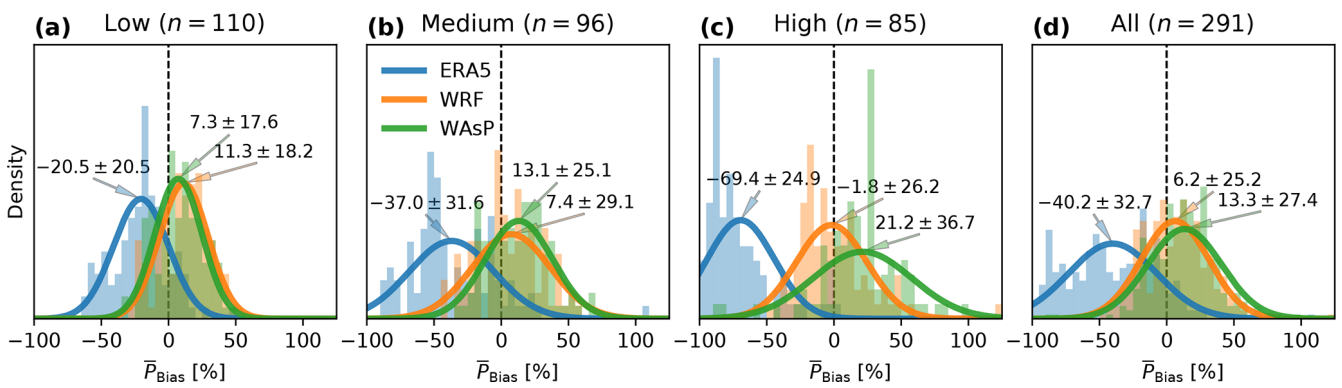

Figure 12. Distributions of the biases in mean generated power for the various stages of the model chain grouped by ruggedness index (RIX) category: low (a), medium (b), high (c), and all of the samples combined (d). The power was estimated by the modelled and observed wind climates combined with the NREL 5 MW reference turbine power curve. Fitted normal distributions (lines) are annotated by the mean and standard deviation $(\mu \pm \sigma)$. The number of masts $(n)$ in each category is indicated above the subplots.

The $\mathrm{CEMD}_{\mathrm{WD}}$ samples are not normally distributed, so a $\log (x)$ transformation was made. After the transformation the samples are close to normally distributed (Fig. 13).

The distributions of $\log \left(\mathrm{CEMD}_{\mathrm{WD}}\right)$ is shown in Fig. 13. These show that in low RIX terrain ERA5 estimates the wind direction distributions most accurately, on average, than the other stages of the model chain, but the spread for ERA5 is much greater than for WRF and WAsP. The WRF and WAsP wind direction distributions produce very similar results in simple terrain, although a very slight improvement of WAsP is seen relative to WRF. In medium and high RIX terrain WRF $\left(6.41^{\circ} \pm 1.74\right.$ and $8.83 \pm 2.00^{\circ}$, respectively) estimates the wind direction distributions more accurately than ERA5 $\left(7.27 \pm 1.79^{\circ}\right.$ and $12.57 \pm 1.79^{\circ}$ respectively). WAsP reduces the accuracy of WRF in high RIX terrain, possibly due to over-corrections of the orographically induced turning of the wind in complex orography.

\section{Discussion}

The NEWA mesoscale model setup has advantages and disadvantages. The setup selection process was mainly driven by the model accuracy in terms of reproducing the wind speed distribution from a series of sensitivity experiments. The main focus of the NEWA atlases was in correctly reproducing the wind climate expressed in terms of the wind distribution (EMD) and not in terms of RMSE of the WRF time series. Optimizing for time series accuracy could have led to a different WRF model setup. In addition, computational efficiency considerations (i.e. the domain size) drove the selection of the setup. These aspects are discussed in more detail in Part 1 of this study (Hahmann et al., 2020b). It is important to mention here that the data from the 291 masts used for evaluation were not used for the selection of the WRF model setup used in the NEWA production simulations.

The choice of the domain configuration is one of the most debatable aspects of the mesoscale setup. The choice of having each country (with exceptions, see Hahmann et al., $2020 \mathrm{~b}$ ) covered in one domain was in part motivated by the rationale that wind farm projects rarely cross borders and thus the points of interest for one wind farm should be in one domain only. This should avoid the confusion for the end user that could result if inconsistent time series, which originate from two different domains, are used within one project. However, the "one domain per country" criterion has limitations, for example some large-scale wind systems are generated or modified by orography that is contained in the neighbouring domain. This could be the reason for the lower wind speeds in WRF compared to ERA5 over the Aegean Sea (Fig. 7a), where the TR and GR domains do not contain the orography of the other, which may have an impact on the Etesian wind system that dominates the flow in the region. More details and a comparison to satellite data can be found in Hasager et al. (2020).

The WAsP downscaling methodology is sensitive to the values of surface roughness length used and their representativeness. In this study, the conversion from CORINE land use classes to surface roughnesses relies on several key assumptions: (1) that the 44 classes accurately capture the real variability of land use and (2) that the mapping from land use class to surface roughness length is accurate. However, the accuracy of the maps and surface roughness is unknown. Previous studies have estimated the mean surface roughnesses uncertainties on the order of a factor of $\sim 3$ (Kelly and Jørgensen, 2017). Halving and doubling all the roughnesses in Table 2 leads to mean wind speed errors for the 291 masts in this study of $-0.11 \pm 0.75$ and $0.61 \pm 0.78$ after downscaling with WAsP, showing the wide span of results one can obtained within "reasonable" roughness values.

The traditional WAsP methodology, as opposed to that of WRF-WAsP method used here, involves predicting the wind climate at a target location from a nearby observed wind climate. Thus, the same terrain data are used to estimate correction factors for the generalization and the subsequent prediction at the target location. This means that any mischaracterization of the terrain effects during the generalization step could be partly compensated by corresponding and opposite errors during the prediction step. This compensation 

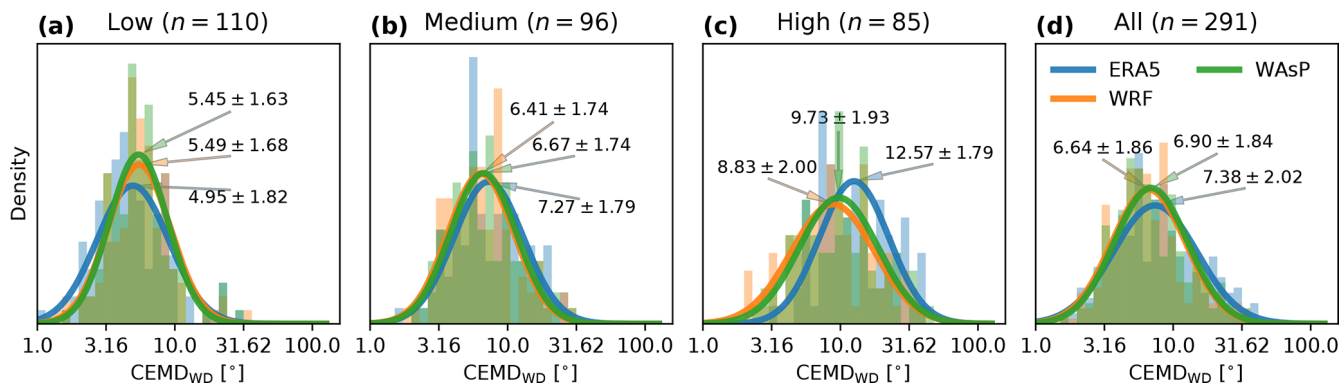

Figure 13. Distributions of the log-transformed samples of circular statistical distance (CEMDWD) between the observed and modelled wind directions for the three stages of the model chain, separated into groups by the ruggedness index (RIX) category: low (a), medium (b), high (c), and all the samples (d). The lines are fitted normal distributions that are annotated by the mean and standard deviation $(\mu \pm \sigma)$ transformed back to physical units of degrees. The number of masts $(n)$ in each category is indicated above each subplot.

does not occur when the wind climate is derived from the WRF model simulations, which use and respond to surface roughness and terrain in a different way to the WAsP flow models. In NEWA, the parameters used in the generalization due to roughness changes (see Hahmann et al., 2020, for more details) were calibrated to generate smooth generalized wind climate estimates across flat coastal zones in northern Europe. No calibration was done for terrain speed up. The use of these parameters can introduce systematic biases in the generalization of the WRF wind climatologies that are translated to the WAsP wind climatologies, but their nature is currently unknown.

Several wind atlases for regions or countries in Europe have been released in recent years (Tammelin et al., 2013; Weiter et al., 2019; Kotroni et al., 2014; Wijnant et al., 2019). They can only be compared indirectly to the NEWA wind atlas because they represent different periods and have been evaluated against different observations (e.g. location, height a.g.l., and duration) to NEWA.

The Finnish wind atlas was validated against data obtained from 20 met masts over a 1-year period with a mean positive bias of around $0.2-0.3 \mathrm{~m} \mathrm{~s}^{-1}$ in the mesoscale model (Tammelin et al., 2013). However, the masts only represent a fairly limited region of the total atlas near Helsinki. The NEWA wind atlas was evaluated against 10 masts in Finland (distributed throughout the country), and we showed (Fig. 10) that WRF generally had small mean wind speed biases over Finland, while ERA5 and WAsP mostly underestimate the mean wind speed slightly. Weiter et al. (2019) created a wind atlas of Germany by statistically correcting mesoscale wind fields for the impact of complex terrain on the flow. They found a relative bias of $10 \%-25 \%$ in power corresponding to $4 \%$ to $10 \%$ for the annual mean wind speed for most sites when evaluating the atlas against 12 wind farms. The observations in our study only contained four masts within Germany. Thus, no comparison is possible between this study and the NEWA wind atlas.

The NEWA wind atlas was evaluated against 11 mostly mainland masts in Greece and generally showed near-zero bias or small underestimates of the mean wind speed for WRF (Fig. 10). This is a big improvement over ERA5, which underestimates the mean wind speed by $\approx 2.5-4 \mathrm{~m} \mathrm{~s}^{-1}$. Most of the masts (10 of 11) are in complex terrain and WAsP tends to overestimate the wind speeds by $\approx 0-2 \mathrm{~m} \mathrm{~s}^{-1}$. Kotroni et al. (2014) made a numerical wind atlas for Greece based on the MM5 mesoscale model and evaluated it against six masts located across Greece. They found that the model overestimates the mean wind speed for mainland sites in Greece and underestimates it slightly for the island of Lemnos in the Aegean Sea. However, the masts are all short $(10 \mathrm{~m}$ or less), and thus are subject to large uncertainties due to the large variance near the surface and are not representative of the weather patterns at wind turbine hub heights.

Relatively small mean wind speed biases are seen for the NEWA WRF results in complex terrain, which is somewhat surprising given that the model does not resolve the complex orographic features. These small mean biases may be due to a compensation of errors: underrepresented speed-up effects on top of the hills and ridges, where the masts are placed, are partly compensated by a general overestimation of the wind speed over hills resulting from unresolved orographic drag (Jimenez and Dudhia, 2012). This could be investigated further by evaluating the results over a more evenly distributed network of masts, which included valleys.

The NEWA wind atlas presents, for the first time, a comprehensive evaluation against a large dataset of tall masts that is synchronized in time and spans most land regions covered by the atlas. There are, however, still significant limitations of the evaluation due to the relatively small number of available masts in the dataset. First, the database lacks masts in some regions that are key for wind energy, based on the number of installations and ongoing development, including Denmark, Germany, Belgium, Spain, and the Netherlands. Second, masts are often clustered at prospect sites, which means that overall fewer regions are represented. Third, masts are positioned at wind energy relevant positions and not evenly distributed across different types of terrain, i.e. the top of hills and ridges are more frequently sampled than valleys 
and mountain basins. However, this is not all bad because the wind atlas is targeted for areas with possible wind energy development.

It is not feasible to evaluate the NEWA long-term wind atlas itself because the wind atlas represents the period between 1989 and 2018 and no measurements cover that entire period. In addition, measurement heights differ from mast to mast and rarely coincide with the fixed heights of the atlas. Therefore, the evaluation is based on mast-specific wind climates estimated with the NEWA model chain, modified slightly to be flexible for the purpose of the evaluation. The main differences between the methods used for the longterm atlas and for the evaluation presented here are as follows: (1) the evaluation method represents wind climates as a histogram (bins) throughout, while the long-term method fits a Weibull distribution during the generalization step, and (2) the evaluation method assumes neutral stability for vertical extrapolation and makes no stability correction to the wind climate, while the long-term method assumes slightly stable conditions (on land) for vertical extrapolation and makes a stability correction (Kelly and Troen, 2016) during the generalization step. These two factors should add very small differences between the two methods of evaluation.

In complex terrain, further downscaling of the WRF model wind climatologies via high-resolution dynamical flow models, e.g. large-eddy simulation (LES) or unsteady ReynoldsAveraged Navier-Stokes (uRANS) models, is expected to improve the accuracy of the estimated wind climates (Sanz Rodrigo et al., 2017). However, this is at a much greater computational cost than the linearized flow model utilized for NEWA and currently cannot be done on a European scale even using modern supercomputers. However, for single complex terrain sites of interest these methods are already being applied (e.g. Duraisamy et al., 2014; Rodrigues et al., 2016; Olsen, 2018; Santoni et al., 2018; Barcons et al., 2019). To improve the accuracy of future wind atlases, it may thus be appropriate to separately downscale the wind climates in regions with highly complex terrain using a CFD model, while using more simple methods like WAsP for most regions.

\section{Summary and conclusions}

The NEWA wind atlas was created and released to the general public on 27 June 2019. The NEWA wind atlas provides a mesoscale and microscale wind climatology for the countries of the European Union plus Norway, Switzerland, the Balkans, and Turkey that is based on simulations with the WRF mesoscale and WAsP microscale model. The mesoscale model simulations were forced by initial and boundary conditions from ERA5 and sea surface temperatures and sea ice from OSTIA (Donlon et al., 2012). The atlas includes atmospheric and surface time series derived from the WRF model simulations for 30 years, with a half- hourly resolution at seven wind energy relevant heights and $3 \mathrm{~km}$ horizontal grid spacing. The microscale model layer provides mean wind speed and power density at three levels $(50,100$, and $150 \mathrm{~m}$ a.g.l.) at a horizontal grid spacing of $50 \mathrm{~m}$. The simulations for the mesoscale database were conducted using a high degree of automation on the HPC cluster MareNostrum 4 between April 2018 and March 2019 using a setup that was defined based on extensive sensitivity tests that are documented in the first part of this study (Hahmann et al., 2020b). The microscale downscaling was carried out on an HPC system at DTU.

The NEWA model chain, which downscales the wind climatology from ERA5 to WRF to WAsP, was validated using wind measurements from 291 European tall masts. The model error was found to be related to the orographic complexity surrounding each mast, which was characterized using the ruggedness index (RIX). The main findings of the evaluation are as follows.

- The average mean wind speed bias for the 291 masts is $-1.50 \pm 1.30 \mathrm{~m} \mathrm{~s}^{-1}$ for ERA5, $0.02 \pm 0.78 \mathrm{~m} \mathrm{~s}^{-1}$ for WRF, and $0.28 \pm 0.76 \mathrm{~m} \mathrm{~s}^{-1}$ for WAsP.

- The results for the masts in simple orography shows that downscaling the WRF wind climates using WAsP reduces the mean wind speed bias and spread from $0.21 \pm 0.54 \mathrm{~m} \mathrm{~s}^{-1}$ to $0.05 \pm 0.49 \mathrm{~m} \mathrm{~s}^{-1}$ for $\mathrm{WRF}$ and WAsP, respectively

- For the masts located in the most complex orography, downscaling the WRF wind climates using WAsP resulted in large overestimations of the mean wind speed. This indicates that the microscale model, WAsP, is overestimating the orographic speed-up incurred by the steep terrain. This is a known behaviour of the WAsP linearized flow model, which assumes attached flow and gentle slopes (Jackson and Hunt, 1975).

- The average mean power generation biases (using the NREL $5 \mathrm{MW}$ reference turbine power curve) for all masts are $-40.2 \% \pm 32.7 \%$ (ERA5), $6.2 \% \pm 25.2 \%$ (WRF), and $13.3 \% \pm 27.4 \%$ (WAsP). The distribution of the biases among complexity classes is similar to that seen in the biases of the wind speed.

- The wind direction differences were quantified using the Earth Mover's Distance (EMD) based on a circular distance matrix. In simple orography ERA5 wind direction distributions are, on average, more accurate than WRF and WAsP. In complex orography the WRF wind direction distributions are most accurate, followed by WAsP, and then ERA5.

The New European Wind Atlas is publicly available for visual investigations and data download via https://map. neweuropeanwindatlas.eu/ (last access: 20 October 2020). 
In the future, the wind atlas could be enhanced by additional layers, e.g. for extreme winds and additional turbulence quantities or further statistical analyses of wind direction or other atmospheric parameters. Further evaluation, especially in countries with limited mast data in our study, and the computation of derived quantities could enhance the wind atlas product in the future. Additional validation of the wind atlas in comparison to production data from existing wind farms could give further insight into the accuracy of the wind atlas. However, in most cases these data are confidential, and thus there might be difficulties arising from non-disclosure agreements. The wind atlas website could be enhanced for further filtering of the data, e.g. a selection of the model based on RIX. In general, more research is needed to improve the understanding of the relationships between modelled mesoscale and microscale winds and local measurements.

Code availability. The WRF model code is open-source and can be obtained from NCAR (2020). It should be installed following the general instructions given there. In the NEWA production run, we used WRF version 3.8.1 and modified it as described in Hahmann et al. (2020b). The code modifications, namelists, tables, and domain files we used are available from the NEWA GitHub repository, (https://github.com/newa-wind/Mesoscale; last access: 20 October 2020) and permanently indexed in Zenodo (Hahmann et al., 2020a). 
Appendix A: Mesoscale wind atlas parameters

Table A1. Overview of the final wind atlas parameters that were stored in netCDF files following CF-1.6 conventions. The four-dimensional variables are given at 50,75, 100, 150, 200, 250, and $500 \mathrm{~m}$ a.g.l. All three- and four-dimensional variables are provided at $30 \mathrm{~min}$ time intervals. A post-processing script (written in python) that calculates these parameters is given in: https://github.com/newa-wind/Mesoscale (last access: 20 October 2020).

\begin{tabular}{|c|c|c|c|}
\hline Short name & Long name & units & dimensions \\
\hline$T$ & Air temperature & $\mathrm{K}$ & 4 \\
\hline TKE & Turbulent kinetic energy & $\mathrm{m}^{2} \mathrm{~s}^{-2}$ & 4 \\
\hline WS & Wind speed & $\mathrm{ms}^{-1}$ & 4 \\
\hline WD & Wind direction & $\circ$ & 4 \\
\hline PD & Power density & $\mathrm{Wm}^{-2}$ & 4 \\
\hline QVAPOR & Water vapour mixing ratio & 1 & 4 \\
\hline ABLAT_CYL & Ice ablation on standard cylinder & $\mathrm{kg}$ & 3 \\
\hline ACCRE_CYL & Ice accretion on standard cylinder & $\mathrm{kg}$ & 3 \\
\hline HFX & Surface sensible heat flux & $\mathrm{W} \mathrm{m}^{-2}$ & 3 \\
\hline LH & Surface latent heat flux & $\mathrm{Wm}^{-2}$ & 3 \\
\hline PRECIP & Precipitation rate & $\mathrm{kg} \mathrm{m}^{2}$ & 3 \\
\hline PBLH & PBL height & $\mathrm{m}$ & 3 \\
\hline PSFC & Surface pressure & $\mathrm{Pa}$ & 3 \\
\hline Q2 & Specific humidity at $2 \mathrm{~m}$ & 1 & 3 \\
\hline RHO & Air density & $\mathrm{kg} \mathrm{m}^{-3}$ & 3 \\
\hline RMOL & Inverse Obukhov length & $\mathrm{m}^{-1}$ & 3 \\
\hline SEAICE & Sea ice fraction & 1 & 3 \\
\hline SWDDNI & Shortwave direct normal radiation & $\mathrm{W} \mathrm{m}^{-2}$ & 3 \\
\hline SWDDIR & Shortwave diffuse incident radiation & $\mathrm{W} \mathrm{m}^{-2}$ & 3 \\
\hline $\mathrm{T} 2$ & Air temperature at $2 \mathrm{~m}$ & $\mathrm{~K}$ & 3 \\
\hline TSK & Surface skin temperature & $\mathrm{K}$ & 3 \\
\hline UST & Friction velocity & $\mathrm{m} \mathrm{s}^{-1}$ & 3 \\
\hline WD10 & Wind direction at $10 \mathrm{~m}$ & $\circ$ & 3 \\
\hline WS10 & Wind speed at $10 \mathrm{~m}$ & $\mathrm{~ms}^{-1}$ & 3 \\
\hline ZNT & Surface aerodynamic roughness length & $\mathrm{m}$ & 3 \\
\hline ALPHA & Map projection distortion & $\circ$ & 2 \\
\hline HGT & Surface elevation & $\mathrm{m}$ & 2 \\
\hline LANDMASK & Landmask ( 1 for land, 0 for water) & 1 & 2 \\
\hline LU_INDEX & Dominant land use category (USGS) & - & 2 \\
\hline XLAT & Centre latitude of grid cell & $\circ$ & 2 \\
\hline XLON & Centre longitude of grid cell & $\circ$ & 2 \\
\hline Times & Time & UTC & 1 \\
\hline
\end{tabular}




\section{Appendix B: Land use and roughness length conversion}

Table B1. Lookup table for the surface roughness length as a function of the USGS land use category in the NEWA and default NCAR WRF model configuration. Only values changed from the default are shown.

\begin{tabular}{llrr}
\hline USGS type & Land use land cover class & $\begin{array}{r}\mathrm{z}_{0} \text { NEWA } \\
(\mathrm{m})\end{array}$ & $\begin{array}{r}\mathrm{z}_{0} \text { WRF orig } \\
\text { range }(\mathrm{m})\end{array}$ \\
\hline 2 & Dryland Cropland and Pasture & 0.10 & $0.05-0.15$ \\
3 & Irrigated Cropland and Pasture & 0.10 & $0.02-0.10$ \\
4 & Mixed Dryland/Irrigated Cropland and Pasture & 0.10 & $0.05-0.15$ \\
5 & Cropland/Grassland Mosaic & 0.10 & $0.05-0.14$ \\
7 & Grassland & 0.10 & $0.10-0.12$ \\
8 & Shrubland & 0.12 & $0.01-0.05$ \\
9 & Mixed Shrubland/Grassland & 0.12 & $0.01-0.06$ \\
11 & Deciduous Broadleaf Forest & 0.90 & 0.5 \\
12 & Deciduous Needleleaf Forest & 0.90 & 0.5 \\
13 & Evergreen Broadleaf Forest & 0.90 & 0.5 \\
14 & Evergreen Needleleaf Forest & 0.90 & 0.5 \\
15 & Mixed Forest & 0.50 & $0.20-0.50$ \\
17 & Tidal zone & 0.001 & 0.20 \\
\hline
\end{tabular}

a Originally called "Herbaceous Wetland" in the default WRF vegetation table. 
Author contributions. MD and BTO wrote the first draft and took over responsibility in automating the mesoscale (MD) and microscale simulations, as well as the evaluation with tall masts (BTO). MD, BTO, BW, ANH, JoB, YE, EG-B, JFG-R, JN, MS$\mathrm{M}$, and TS conducted simulations for the NEWA mesoscale wind atlas. NND and WT automatized and optimized the microscale and mesoscale simulations on the HPC systems. MZ participated in the tall mast evaluation and discussions. JaB contributed to aspects of the model chain downscaling to microscale, interpretation of the evaluation, and defining atlas outputs. All authors participated in the writing, editing, and internal reviews of the manuscript.

Competing interests. The WAsP software that was used to produce the NEWA microscale wind atlas is developed and commercially sold by DTU Wind Energy.

Acknowledgements. The computing resources for the calculation of the mesoscale wind atlas were made available through a PRACE grant (project no. 2017174128) between April 2018 and March 2019. The microscale atlas was computed between April 2019 and June 2019 on the DTU "Sophia" HPC cluster. A feasibility study and many tests for the production run were carried out on the HPC cluster EDDY located at the University of Oldenburg and funded by the Federal Ministry for Economic Affairs and Energy under grant no. 0324005 . Access to the tall mast data used for the evaluation have kindly been granted by Vestas Wind Systems A/S. The authors are grateful to Yavor Hristov from Vestas for helping to make the mast data available. The WRF model simulations were initialized using ERA5 and OSTIA data downloaded from ECMWF, Copernicus Climate Change Service Climate Data Store, and Copernicus Marine Environment Monitoring Service. The authors are grateful to Mark Kelly from DTU Wind energy for valuable comments and discussions; to the technical staff at PRACE, DTU, and the University of Oldenburg for assistance and maintenance of the systems; and to Nazka Maps for making the NEWA wind atlas website. Data processing and visualization for this study was made using the python programming language and involved extensive use of the following software packages: NumPy (Oliphant, 2006; Van Der Walt et al., 2011), SciPy (Jones et al., 2001), pandas (McKinney, 2010), Dask (Dask Development Team, 2016), xarray (Hoyer and Hamman, 2017), Matplotlib (Hunter, 2007), and scikitlearn (Pedregosa et al., 2011). The authors are grateful for the tools provided by the open-source community, which has benefited the making of this study tremendously.

Financial support. The European Commission (EC) partly funded NEWA (NEWA - New European Wind Atlas) through FP7 (topic FP7-ENERGY.2013.10.1.2). The authors of this paper acknowledge the support from the Federal Ministry for the Economic Affairs and Energy, on the basis of the decision by the German Bundestag (grant no. 0325832A/B); the Danish Energy Authority (EUDP 14II, 64014-0590); Latvijas Zinatnu Akademija (Latvia - grant no. Z/16/1397); the Ministerio de Economía y Competitividad (Spain; grant nos. PCIN-2014-017-C07-03, PCIN-2016-176, PCIN-2014017-C07-04, PCIN-2016-009, PCIN-2014-013-C07-04, and PCIN2016-080); the Scientific and Technological Research Council of
Turkey (grant no. 215M386). Mariano Sastre-Marugán additionally acknowledges support from the Spanish Ministerio de Educación, Cultura y Deporte through the "José Castillejo" Fellowship (grant no. CAS18/00316).

Review statement. This paper was edited by Chiel van Heerwaarden and reviewed by two anonymous referees.

\section{References}

Anderson, J. R., Hardy, E. E., Roach, J. T., and Witmer, R. E.: A land use and land cover classification system for use with remote sensor data, Tech. rep., United States Geological Service, available at: https://pubs.usgs.gov/pp/0964/report.pdf (last access: 20 October 2020), 1976.

Badger, J., Frank, H., Hahmann, A. N., and Giebel, G.: Wind-climate estimation based on mesoscale and microscale modeling: Statistical-dynamical downscaling for wind energy applications, J. Appl. Meteorol. Clim., 53, 1901-1919, https://doi.org/10.1175/JAMC-D-13-0147.1, 2014.

Badger, J., Sempreviva, A., Söderberg, S., Costa, P., Simoes, T., Estanqueiro, A., Gottschall, J., Dörenkämper, M., Callies, D., Navarro Montesinos, J., González Rouco, J., Garcia Bustamante, E., and Bauwens, I.: Report on Link to Global Wind Atlas and National Wind Atlases - Deliverable D4.7, Technical Report, 37 pages 4.7, Technical University of Denmark, https://doi.org/10.5281/zenodo.3243193, 2018.

Barcons, J., Avila, M., and Folch, A.: Diurnal cycle RANS simulations applied to wind resource assessment, Wind Energy, 22, 269-282, https://doi.org/10.1002/we.2283, 2019.

Copernicus Land Monitoring Service: CORINE Land Cover, available at: https://land.copernicus.eu/pan-european/ corine-land-cover, last access: 22 October 2019.

Danielson, J. J. and Gesch, D. B.: Global multi-resolution terrain elevation data 2010 (GMTED2010), Tech. Rep. 2011-1073, U.S. Geological Survey Open-File Report, available at: https://pubs. usgs.gov/of/2011/1073/ (last access: 19 October 2019), 2011.

Dask Development Team: Dask: Library for dynamic task scheduling, available at: https://dask.org (last access: 19 October 2019), 2016.

de Ferranti, J.: Digital Elevation Data, available at: http:// viewfinderpanoramas.org/dem 3.html (last access: 23 January 2020), 2014.

Donlon, C. J., Martin, M., Stark, J. D., Roberts-Jones, J., Fiedler, E., and Wimmer, W.: The Operational Sea Surface Temperature and Sea Ice analysis (OSTIA), Remote Sens. Environ., 116, 140-158, https://doi.org/10.1016/j.rse.2010.10.017, 2012.

Dörenkämper, M., Optis, M., Monahan, A., and Steinfeld, G.: On the Offshore advection of Boundary-Layer Structures and the Influence on Offshore Wind Conditions, Bound.-Lay. Meteorol., 155, 459-482, https://doi.org/10.1007/s10546-015-0008-x, 2015.

Doubrawa, P., Barthelmie, R. J., Pryor, S. C., Hasager, C. B., Badger, M., and Karagali, I.: Satellite winds as a tool for offshore wind resource assessment: The Great Lakes Wind Atlas, Remote Sens. Environ., 168, 349-359, https://doi.org/10.1016/j.rse.2015.07.008, 2015. 
Draxl, C., Clifton, A., Hodge, B.-M., and McCaa, J.: The Wind Integration National Dataset (WIND) Toolkit, Appl. Energ., 151, 355-366, https://doi.org/10.1016/j.apenergy.2015.03.121, 2015.

Drüke, S., Steinfeld, G., Heinemann, D., and Günther, R.: Generation of a wind and stability atlas for the optimized utilization of offshore wind resources in the North Sea Region, Poster Presentation at EGU 2014, Vienna EGU2014-14375, Geophysical Research Abstracts - Volume 16, available at: https://www.muk.uni-hannover.de/uploads/tx_ tkpublikationen/Poster_EGU_20140424_final_01.pdf (last access: 19 October 2019), 2014.

Duraisamy, V. J., Dupont, E., and Carissimo, B.: Downscaling wind energy resource from mesoscale to microscale model and data assimilating field measurements, J. Phys.-Conf. Ser., 555, 012031, https://doi.org/10.1088/1742-6596/555/1/012031, 2014.

Farr, T., Rosen, P., Caro, E., Crippen, R., Duren, R., Hensley, S., Kobrick, M., Paller, M., Rodriguez, E., Roth, L., and Seal, D.: The shuttle radar topography mission, Rev. Geophys., 45, 2, https://doi.org/10.1029/2005RG000183, 2007.

Gelaro, R., McCarty, W., Suárez, M. J., Todling, R., Molod, A., Takacs, L., Randles, C. A., Darmenov, A., Bosilovich, M. G., Reichle, R., Wargan, K., Coy, L., Cullather, R., Draper, C., Akella, S., Buchard, V., Conaty, A., da Silva, A. M., Gu, W., Kim, G.K., Koster, R., Lucchesi, R., Merkova, D., Nielsen, J. E., Partyka, G., Pawson, S., Putman, W., Rienecker, M., Schubert, S. D., Sienkiewicz, M., and Zhao, B.: The Modern-Era Retrospective Analysis for Research and Applications, Version 2 (MERRA-2), J. Climate, 30, 5419-5454, https://doi.org/10.1175/JCLI-D-160758.1, 2017.

González-Rouco, J. F., García-Bustamante, E., Hahmann, A. N., Karagili, I., Navarro, J., Olsen, B. T., Sile, T., and Witha, B.: NEWA Report on uncertainty quantification Deliverable D4.4, Tech. rep., Univ. Complutense Madrid, https://doi.org/10.5281/zenodo.3382572, 2019.

GWA: Global Wind Atlas, available at: https://www. globalwindatlas.info/, last access: 18 October 2019.

Hahmann, A., Pian, A., Lennard, C., and Mortensen, N.: Mesoscale Modelling for the Wind Atlas of South Africa (WASA) Project - Phase II, Tech. Rep. E-0188, DTU Wind Energy, Denmark, available at: https://orbit.dtu.dk/files/192964222/DTU_ Wind_Energy_E_0188.pdf (last access: 20 October 2020), 2018.

Hahmann, A. N., Badger, J., Vincent, C. L., Kelly, M. C., Volker, P. J. H., and Refslund, J.: Mesoscale modeling for the wind atlas for South Africa (WASA) Project, Tech. Rep. TR-0050, DTU Wind Energy, available at: https://orbit.dtu.dk/files/107110172/DTU_ Wind_Energy_E_0050.pdf (last access: 19 October 2019), 2014.

Hahmann, A. N., Vincent, C. L., Peña, A., Lange, J., and Hasager, C. B.: Wind climate estimation using WRF model output: Method and model sensitivities over the sea, Int. J. Climatol., 35, 3422-3439, https://doi.org/10.1002/joc.4217, 2015.

Hahmann, A. N., Olsen, B. T., Volker, P. J. H., Mortensen, N. G., and Badger, J.: Generalization of WRF-derived wind climatologies for validation and coupling of mesoscale and microscale models, Wind Energy Science, in preparation, 2020.

Hahmann, A. N., Davis, N. N., Dörenkämper, M., Sile, T., Witha, B., and Trei, W.: WRF configuration files for NEWA mesoscale ensemble and production simulations, Zenodo, https://doi.org/10.5281/zenodo.3709088, 2020a.
Hahmann, A. N., Sile, T., Witha, B., Davis, N. N., Dörenkämper, M., Ezber, Y., García-Bustamante, E., Fidel González Rouco, J., Navarro, J., Olsen, B. T., and Söderberg, S.: The making of the New European Wind Atlas - Part 1: Model sensitivity, Geosci. Model Dev., 13, 5053-5078, https://doi.org/10.5194/gmd-135053-2020, 2020b.

Hasager, C. B., Hahmann, A. N., Ahsbahs, T., Karagali, I., Sile, T., Badger, M., and Mann, J.: Europe's offshore winds assessed with synthetic aperture radar, ASCAT and WRF, Wind Energ. Sci., 5, 375-390, https://doi.org/10.5194/wes-5-375-2020, 2020.

Hersbach, H. and Dick, D.: ERA5 reanalysis is in production, available at: http://www.ecmwf.int/en/newsletter/147/news/ era5-reanalysis-production (last access: 22 October 2019), 2016.

Hong, S.-Y., Dudhia, J., and Chen, S.-H.: A revised approach to ice microphysical processes for the bulk parameterization of clouds and precipitation, Mon. Weather Rev., 132, 103-120, https://doi.org/10.1175/15200493(2004)132<0103:ARATIM>2.0.CO;2, 2004.

Horvath, K., Koracin, D., Vellore, R., Jiang, J., and Belu, R.: Sub-kilometer dynamical downscaling of nearsurface winds in complex terrain using WRF and MM5 mesoscale models, J. Geophys. Res.-Atmos., 117, D11111, https://doi.org/10.1029/2012JD017432, 2012.

Hoyer, S. and Hamman, J.: xarray: N-D labeled arrays and datasets in Python, J. Open Res. Softw., 5, p. 10, https://doi.org/10.5334/jors.148, 2017.

Hunter, J. D.: Matplotlib: A 2D graphics environment, Comput. Sci. Eng., 9, 99-104, https://doi.org/10.1109/MCSE.2007.55, 2007.

Iacono, M. J., Delamere, J. S., Mlawer, E. J., Shephard, M. W., Clough, S. A., and Collins, W. D.: Radiative forcing by long-lived greenhouse gases: Calculations with the AER radiative transfer models, J. Geophys. Res., 113, D13103, https://doi.org/10.1029/2008JD009944, 2008.

Jackson, P. S. and Hunt, J. C. R.: Turbulent wind flow over a low hill, Q. J. Roy. Meteorol. Soc., 101, 929-955, https://doi.org/10.1002/qj.49710143015, 1975.

Janjic, Z. I. and Zavisa, I.: The Step-Mountain Eta Coordinate Model: Further developments of the convection, viscous sublayer, and turbulence closure schemes, Mon. Weather Rev., 122, 927-945, https://doi.org/10.1175/15200493(1994)122<0927:TSMECM>2.0.CO;2, 1994.

Jimenez, P. A. and Dudhia, J.: Improving the Representation of Resolved and Unresolved Topographic Effects on Surface Wind in the WRF Model, J. Appl. Meteorol. Clim., 51, 300-316, https://doi.org/10.1175/JAMC-D-11-084.1, 2012.

Jimenez, P. A., Fidel Gonzalez-Rouco, J., Garcia-Bustamante, E., Navarro, J., Montavez, J. P., Vila-Guerau de Arellano, J., Dudhia, J., and Munoz-Roldan, A.: Surface Wind Regionalization over Complex Terrain: Evaluation and Analysis of a HighResolution WRF Simulation, J. Appl. Meteorol. Clim., 49, 268287, https://doi.org/10.1175/2009JAMC2175.1, 2010.

Jones, E., Oliphant, T., Peterson, P., Virtanen, P., Gommers, R., Oliphant, T. E., Haberland, M., Reddy, T., Cournapeau, D., Burovski, E., Peterson, P., Weckesser, W., Bright, J., van der Walt, S. J., Brett, M., Wilson, J., Jarrod Millman, K., Mayorov, N., Nelson, A. R. J., Jones, E., Kern, R., Larson, E., Carey, C. J., Polat, İ., Feng, Y., Moore, E. W., VanderPlas, J., Laxalde, D., Perktold, J., Cimrman, R., Henriksen, I., Quintero, E. A., Harris, C. R., Archibald, A. M., Ribeiro, A. H., Pedregosa, F., van Mul- 
bregt, P., and SciPy 1.0 Contributors: SciPy 1.0: Fundamental Algorithms for Scientific Computing in Python, Nat. Methods, 17, 261-272, https://doi.org/10.1038/s41592-019-0686-2, 2020.

Jonkman, J. M., Butterfield, S., Musial, W., and Scott, G.: Definition of a 5-MW reference wind turbine for offshore system development, Technical Report, 75 pages, NREL/TP-500-38060, National Renewable Energy Laboratory, 1617 Cole Boulevard, Golden, Colorado 80401-3393, https://doi.org/10.2172/947422, 2009.

Kain, J. S.: The Kain-Fritsch convective parameterization: An update, J. Appl. Meteorol. Clim., 43, 170-181, https://doi.org/10.1175/15200450(2004)043<0170:TKCPAU>2.0.CO;2, 2004.

Karagali, I., Badger, M., Hahmann, A. N., Peña, A., Hasager, C. B., and Sempreviva, A. M.: Spatial and temporal variability of winds in the Northern European Seas, Renew. Energ., 57, 200-210, 2013.

Kelly, M. and Jørgensen, H. E.: Statistical characterization of roughness uncertainty and impact on wind resource estimation, Wind Energy Sci., 2, 189-209, https://doi.org/10.5194/wes-2189-2017, 2017.

Kelly, M. and Troen, I.: Probabilistic stability and "tall" wind profiles: theory and method for use in wind resource assessment, Wind Energy, 19, 227-241, 2016.

Kotroni, V., Lagouvardos, K., and Lykoudis, S.: High-resolution model-based wind atlas for Greece, Renew Sust. Energ. Rev., 30, 479-489, https://doi.org/10.1016/j.rser.2013.10.016, 2014.

Liu, Y., Warner, T., Liu, Y., Vincent, C., Wu, W., Mahoney, B., Swerdlin, S., Parks, K., and Boehnert, J.: Simultaneous nested modeling from the synoptic scale to the LES scale for wind energy applications, J. Wind Eng. Ind. Aerod., 99, 308-319, https://doi.org/10.1016/j.jweia.2011.01.013, 5th International Symposium on Computational Wind Engineering (CWE2010), Chapel Hill, NC, MAY 23-27, 2010, 2011.

Lundquist, J., DuVivier, K., Kaffine, D., and Tomaszewski, J.: Costs and consequences of wind turbine wake effects arising from uncoordinated wind energy development, Nat. Energy, 4, 26-34, https://doi.org/10.1038/s41560-018-0281-2, 2019.

Makkonen, L.: Models for the growth of rime, glaze, icicles and wet snow on structures, Philos. T. Roy. Soc. A, 358, 2913-2939, https://doi.org/10.1098/rsta.2000.0690, 2000.

Mann, J., Angelou, N., Arnqvist, J., Callies, D., Cantero, E., Arroyo, R. C., Courtney, M., Cuxart, J., Dellwik, E., Gottschall, J., Ivanell, S., Kühn, P., Lea, G., Matos, J. C., Palma, J. M. L. M., Pauscher, L., Peña, A., Rodrigo, J. S., Söderberg, S., Vasiljevic, N., and Rodrigues, C. V.: Complex terrain experiments in the New European Wind Atlas, Philos. T. Roy. Soc. A, 375, 20160101, https://doi.org/10.1098/rsta.2016.0101, 2017.

McKinney, W.: Data Structures for Statistical Computing in Python, in: Proceedings of the 9th Python in Science Conference, edited by: van der Walt, S. and Millman, J., 51-56, available at: https://conference.scipy.org/proceedings/scipy2010/ pdfs/mckinney.pdf (last access: 19 October 2019), 2010.

Mellor, G. L. and Yamada, T.: Development of a turbulence closure model for geophysical fluid problems, Rev. Geophys. Space Phys., 20, 851-875, https://doi.org/10.1029/RG020i004p00851, 1982.

Mortensen, N. G.: Wind resource assessment using the WAsP software, Tech. rep., DTU Wind Energy, 2018.
Mortensen, N. G., Said Said, U., and Badger, J.: Wind Atlas for Egypt, available at: https://orbit.dtu.dk/files/52612711/Wind_ Atlas_for_Egypt_paper.pdf (last access: 18 October 2018), 2006.

Mortensen, N. G., Tindal, A., and Landberg, L.: Field validation of the RIX performance indicator for flow in complex terrain., Paper presented at 2008 European Wind Energy Conference and Exhibition, Brussels, Belgium, available at: https://orbit.dtu.dk/ files/6394929/2008_58.pdf (last access: 19 October 2019), 2008.

Mortensen, N. G., Heathfield, D. N., Rathmann, O., and Nielsen, M.: Wind Atlas Analysis and Application Program: WAsP 10 Help Facility, Tech. rep., DTU Wind Energy, available at: https: //orbit.dtu.dk/files/116352660/WAsP_10_Help_Facility.pdf (last access: 20 October 2020), 2011.

Mortensen, N. G., Hansen, J. C., and Kelly, M. C.: Wind Atlas for South Africa (WASA) Western Cape and parts of Northern and Eastern Cape Observational Wind Atlas for 10 Met. Masts in Northern, Western and Eastern Cape Provinces, Tech. Rep. April, DTU Wind Energy, available at: https://orbit.dtu.dk/ws/ files/110948908/DTU_Wind_Energy_E_0072.pdf (last access: 19 October 2019), 2014.

MWKEL: Windatlas Rheinland-Pfalz, Technical report, 48 pages, Ministerium für Wirtschaft, Klimaschutz, Energie und Landesplanung Rheinland-Pfalz, available at: https://mueef.rlp.de/fileadmin/mulewf/Themen/Energie_und_ Strahlenschutz/Energie/1_rlp_windatlas_stand_24072013.pdf (last access: 18 October 2018), 2013.

Nawri, N., Petersen, G., Bjornsson, H., Hahmann, A., Jónasson, K., Hasager, C., and Clausen, N.-E.: The wind energy potential of Iceland, Renew. Energy, 69, 290-299, https://doi.org/10.1016/j.renene.2014.03.040, 2014.

NCAR: WRF Model User's Page, WRF Version 3.8.1, https://doi.org/10.5065/D6MK6B4K, 2020.

Oliphant, T. E.: A guide to NumPy, available at: http://web.mit.edu/ dvp/Public/numpybook.pdf (last access: 19 October 2019), 2006.

Olsen, B. T.: Mesoscale to microscale coupling for determining site conditions in complex terrain, PhD thesis, DTU Wind Energy, https://doi.org/10.11581/00000036, 2018.

Pedregosa, F., Varoquaux, G., Gramfort, A., Michel, V., Thirion, B., Grisel, O., Blondel, M., Prettenhofer, P., Weiss, R., Dubourg, V., Vanderplas, J., Passos, A., Cournapeau, D., Brucher, M., Perrot, M., and Duchesnay, E.: Scikit-learn: Machine Learning in Python, J. Mach. Learn. Res., 12, 2825-2830, 2011.

Peña Diaz, A., Hahmann, A., Hasager, C., Bingöl, F., Karagali, I., Badger, J., Badger, M., and Clausen, N.-E.: South Baltic Wind Atlas: South Baltic Offshore Wind Energy Regions Project, Tech. rep., Technical University of Denmark, available at: https: //orbit.dtu.dk/files/5578113/ris-r-1775.pdf (last access: 20 October 2020), 2011.

Petersen, E. L.: In search of the wind energy potential, J. Renew. Sustain. Energy, 9, 052301, https://doi.org/10.1063/1.4999514, 2017.

Petersen, E. L., Troen, I., Jørgensen, H. E., and Mann, J.: Are local wind power resources well estimated?, Environ. Res. Lett., 8, 011005, https://doi.org/10.1088/1748-9326/8/1/011005, 2013.

Pineda, N., Jorba, O., Jorge, J., and Baldasano: Using NOAAAVHRR and SPOT-VGT data to estimate surface parameters: Application to a mesoscale meteorological model, 1st Int. Symp. Recent Adv. Quant. Remote Sens., 1161, 16-20, https://doi.org/10.1080/0143116031000115201, 2002. 
Poulter, B., MacBean, N., Hartley, A., Khlystova, I., Arino, O., Betts, R., Bontemps, S., Boettcher, M., Brockmann, C., Defourny, P., Hagemann, S., Herold, M., Kirches, G., Lamarche, C., Lederer, D., Ottlé, C., Peters, M., and Peylin, P.: Plant functional type classification for earth system models: results from the $\mathrm{Eu}-$ ropean Space Agency's Land Cover Climate Change Initiative, Geosci. Model Dev., 8, 2315-2328, https://doi.org/10.5194/gmd8-2315-2015, 2015.

PyWAsP: PyWAsP, available at: https://www.wasp.dk/, last access: 9 January 2020.

Rodrigues, C. V., Palma, J. M. L. M., and Rodrigues, Á. H.: Atmospheric Flow over a Mountainous Region by a OneWay Coupled Approach Based on Reynolds-Averaged Turbulence Modelling, Bound.-Lay. Meteorol., 159, 407-437, https://doi.org/10.1007/s10546-015-0116-7, 2016.

Rohrig, K., Berkhout, V., Callies, D., Durstewitz, M., Faulstich, S., Hahn, B., Jung, M., Pauscher, L., Seibel, A., Shan, M., Siefert, M., Steffen, J., Collmann, M., Czichon, S., Dörenkämper, M., Gottschall, J., Lange, B., Ruhle, A., Sayer, F., Stoevesandt, B., and Wenske, J.: Powering the 21 st century by wind energy - Options, facts, figures, Appl. Phys. Rev., 6, 031303, https://doi.org/10.1063/1.5089877, 2019.

Saha, S., Moorthi, S., Wu, X., Wang, J., Nadiga, S., Tripp, P., Behringer, D., Hou, Y.-T., Chuang, H.-Y., Iredell, M., Ek, M., Meng, J., Yang, R., Mendez, M.P., van den Dool, H., Zhang, Q., Wang, W., Chen, M., and Becker, E.: The NCEP climate forecast system version 2, J. Climate, 27, 2185-2208, https://doi.org/10.1175/JCLI-D-12-00823.1, 2014.

Santoni, C., García-Cartagena, E., Ciri, U., Iungo, G., and Leonardi, S.: Coupling of mesoscale Weather Research and Forecasting model to a high fidelity Large Eddy Simulation, J. Phys.-Conf. Ser., 1037, 062010, https://doi.org/10.1088/17426596/1037/6/062010, 2018.

Sanz Rodrigo, J., Chávez Arroyo, R., Moriarty, P., Churchfield, M., Kosović, B., Réthoré, P.-E., Hansen, K., Hahmann, A., Mirocha, J., and Rife, D.: Mesoscale to microscale wind farm flow modeling and evaluation, WIREs Energy Environ., 6, e214, https://doi.org/10.1002/wene.214, 2017.

Sanz Rodrigo, J., Chavez Arroyo, R. A., Witha, B., Dörenkämper, M., Gottschall, J., Avila, M., Arnqvist, J., Hahmann, A. N., and Sile, T.: The New European Wind Atlas Model Chain, J. Phys.-Conf. Ser., 1452, 012087, https://doi.org/10.1088/17426596/1452/1/012087, 2020.

Sibson, R.: A brief description of natural neighbor interpolation (Chapter 2), in: Interpolating Multivar, Data, 21-36, John Wiley, 1981.

Silva, J., Ribeiro, C., and Guedes, R.: Roughness length classification of Corine Land Cover Classes, Proceedings of EWEC 2007, 710, 110, available at: https: //www.researchgate.net/publication/228474930_Roughness_ length_classification_of_Corine_Land_Cover_classes (last access: 19 October 2019), 2007.

Skamarock, W. C., Klemp, J. B., Dudhia, J., Gill, D. O., Barker, D. M., Duda, M. G., Huang, X.-Y., Wang, W., and Powers, J. G.: A Description of the Advanced Research WRF Version 3, Tech. Rep. NCAR/TN-475+STR, National Center for Atmospheric Research, available at: https://opensky.ucar.edu/islandora/object/ technotes3A500/datastream/PDF/view (last access: 19 October 2019), 2008.
Starkov, A. and Landberg, L.: Wind atlas of Russia, in: World Renew, Energy Congr. VI, 1217-1220, Pergamon, https://doi.org/10.1016/B978-008043865-8/50252-X, 2000.

Storm, B., Dudhia, J., Basu, S., Swift, A., and Giammanco, I.: Evaluation of the Weather Research and Forecasting model on forecasting low-level jets: implications for wind energy, Wind Energy, 12, 81-90, https://doi.org/10.1002/we.288, 2009.

Tammelin, B., Vihma, T., Atlaskin, E., Badger, J., Fortelius, C., Gregow, H., Horttanainen, M., Hyvönen, R., Kilpinen, J., Latikka, J., Ljungberg, K., Mortensen, N. G., Niemelä, S., Ruosteenoja, K., Salonen, K., Suomi, I., and Venäläinen, A.: Production of the Finnish Wind Atlas, Wind Energy, 16, 19-35, https://doi.org/10.1002/we.517, 2013.

Tewari, M., Chen, F., Wang, W., Dudhia, J., LeMone, M. A., Mitchell, K., Ek, M., Gayno, G., Wegiel, J., and Cuenca, R. H.: Implementation and verification of the unified Noah land surface model in the WRF model., in: 20th conference on weather analysis and forecasting/16th conference on numerical weather prediction, Seattle, 12-16 January 2004, AMS, available at: https://ams.confex.com/ams/84Annual/ techprogram/paper_69061.htm (last access: 19 October 2019), 2004.

Troen, I. and Petersen, E. L.: European Wind Atlas, Published for the Commission of the European Communities, DirectorateGeneral for Science, Research, and Development, Brussels, Belgium by Ris $\varnothing$ National Laboratory, available at: https://orbit. dtu.dk/files/112135732/european_wind_atlas.pdf (last access: 19 October 2019), 1989.

Van Der Walt, S., Colbert, S. C., and Varoquaux, G.: The NumPy array: A structure for efficient numerical computation, Comput. Sci. Eng., 13, 22-30, https://doi.org/10.1109/MCSE.2011.37, 2011.

Vincent, C. L. and Hahmann, A. N.: The Impact of Grid and Spectral Nudging on the Variance of the Near-Surface Wind Speed, J. Appl. Meteorol. Clim., 54, 1021-1038, https://doi.org/10.1175/JAMC-D-14-0047.1, 2015.

Wang, W., Dudhia, J., and Chen, M.: Application of WRF - How to get better performance, National Center for Atmospheric Research, Boulder, CO, USA, available at: http://www2.mmm. ucar.edu/wrf/users/tutorial/201901/chen_best_practices.pdf, last access: 19 December 2019.

Weiter, A., Schneider, M., Peltret, D., and Mengelkamp, H.-T.: Electricity production by wind turbines as a means for the verification of wind simulations, Meteorologische Z., 28, 69-77, https://doi.org/10.1127/metz/2019/0924, 2019.

Westerhellweg, A., Neumann, T., and Riedel, V.: FINO1 Mast Correction, available at: https://pdfs.semanticscholar.org/cf85/ 2b7bc731b071162e537edf45f9578f4ec86e.pdf (last access: 10 August 2020), 2012.

Wijnant, I., van Ulft, B., van Stratum, B., Barkmeijer, J., Onvlee, J., de Valk, C., Knoop, S., Kok, S., Marseille, G., Baltink, H. K., and Stepek, A.: The Dutch Offshore Wind Atlas (DOWA): Description of the dataset, Tech. Rep. TR-380, Royal Netherlands Meteorological Institute (KNMI), available at: https:// www.dutchoffshorewindatlas.nl/ (last access: 21 January 2020), 2019. 